\title{
An update on molecular biology of thyroid cancers
}

\author{
Ozgur Omur $^{\mathrm{a}, *}$, Yusuf Baran ${ }^{\mathrm{b}, * *}$ \\ ${ }^{a}$ Ege University, Faculty of Medicine, Department of Nuclear Medicine, 35100 Bornova, Izmir, Turkey \\ ${ }^{\mathrm{b}} \dot{I}_{z m i r}$ Institute of Technology, Department of Molecular Biology and Genetics, 35430 Urla, İzmir, Turkey
}

Accepted 6 December 2013

\section{Contents}

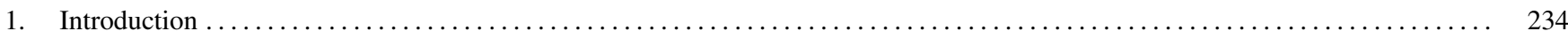

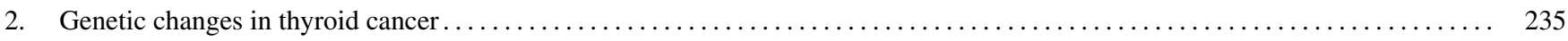

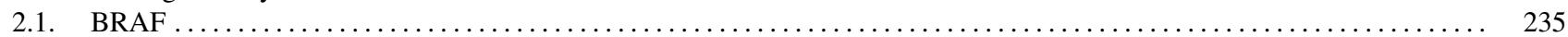

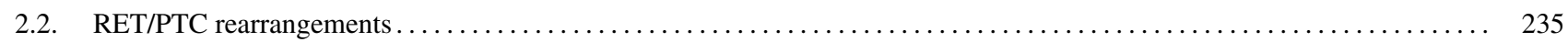

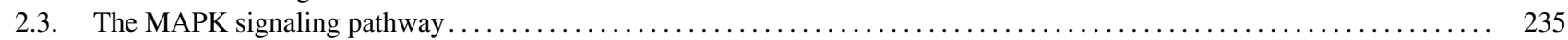

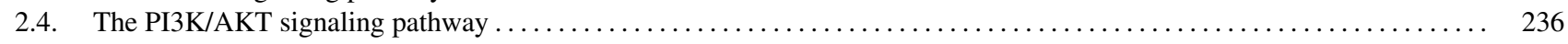

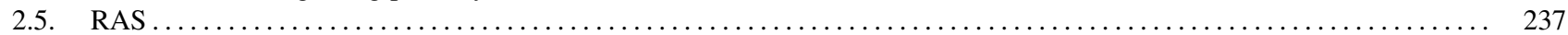

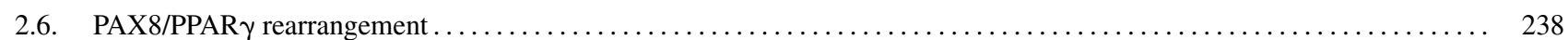

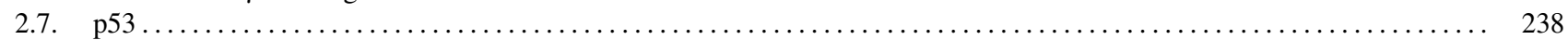

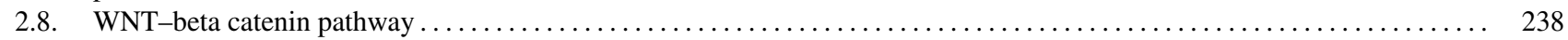

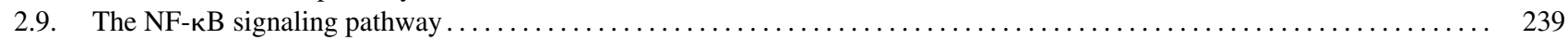

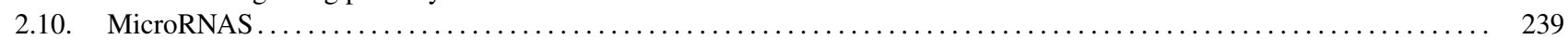

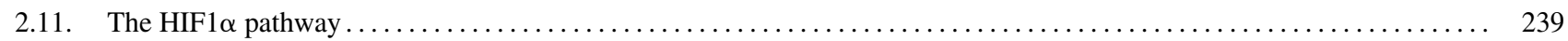

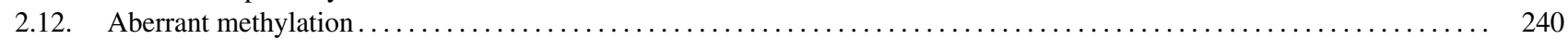

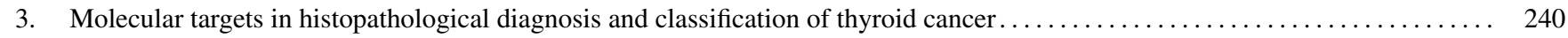

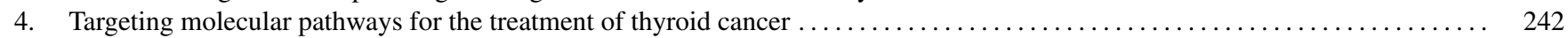

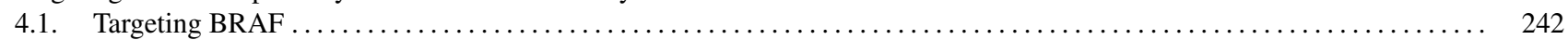

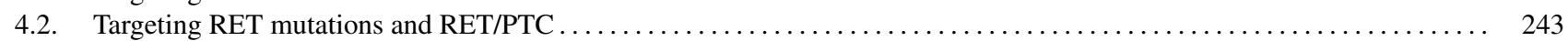

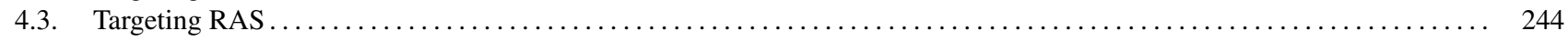

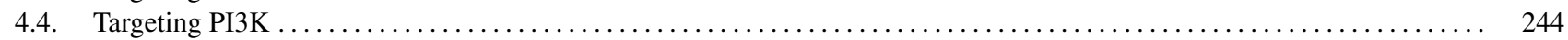

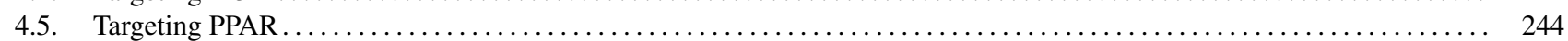

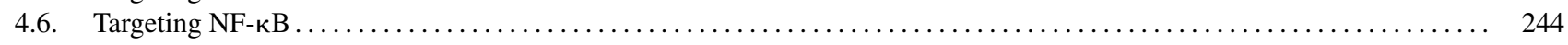

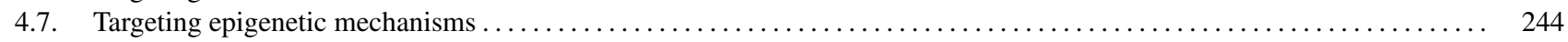

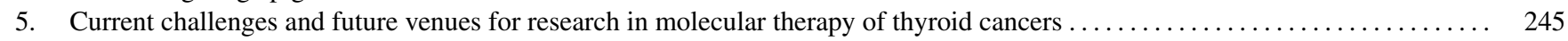

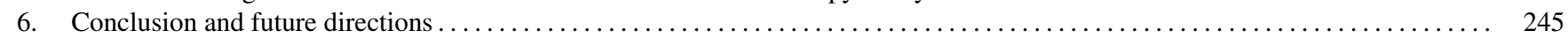

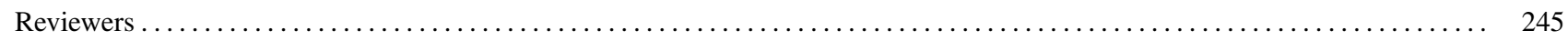

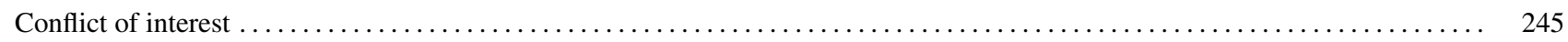

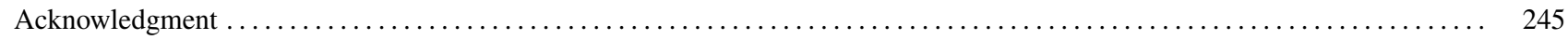

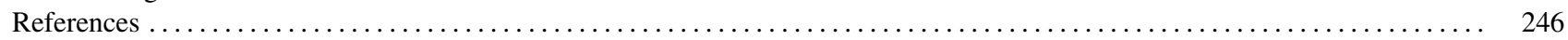

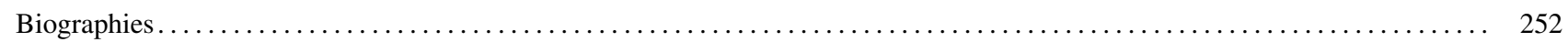

\begin{abstract}
Differentiated thyroid cancer (DTC) is the most common endocrinological malignancy. There are several histological variants such as papillary and follicular thyroid carcinoma. Many patients with well-differentiated subtypes of DTC are cured by surgery alone or with
\end{abstract}

\footnotetext{
* Corresponding author. Tel.: +90 232 3904788; fax: +90 2323434215.

** Corresponding author. Tel.: +90 232 7507315; fax: +90 2327507509.

E-mailaddresses: ozomur@yahoo.com (O. Omur),yusufbaran@iyte.edu.tr (Y. Baran).
} 
radioiodine, while poorly differentiated types usually have a worse prognosis. The aggressiveness of thyroid tumors is closely linked to specific gene alterations.

Several diagnostic and prognostic molecular markers such as BRAF and RAS point mutations; RET/PTC and PAX8/PPAR $\gamma$ gene rearrangements; MAPK, PI3K, p53, Wnt-beta catenin, HIF1 $\alpha$ and NF-kappaB signaling pathways; microRNA profiles and aberrant methylation have been demonstrated in more than $70 \%$ of DTC. Diagnostic use of these molecular markers may be optimized for identifying higher risks of mortality, tumor recurrence and metastatic potential. Understanding the molecular biology of thyroid cancers can be an important avenue for diagnosis and treatment of radioiodine-refractory or inoperable DTC patients with novel molecular targeted therapeutic agents.

(C) 2014 Elsevier Ireland Ltd. All rights reserved.

Keywords: Thyroid cancer; Differentiated thyroid cancer; Molecular biology; BRAF; RET/PTC; PAX8/PPAR $\gamma$

\section{Introduction}

Thyroid cancer is the most common malign endocrine neoplasm originating from follicular or parafollicular thyroid cells. Histopathological classification of thyroid tumors is critical for patient management and for determining the clinical course of the disease. Follicular thyroid cells derived from histological subtypes are follicular thyroid carcinoma (FTC), papillary thyroid carcinoma (PTC), poorly differentiated thyroid carcinoma and anaplastic thyroid carcinoma (ATC). FTC and PTC are classified as differentiated thyroid carcinoma (DTC). Poorly differentiated and ATC also originate from follicular cells, and many cases are believed to develop as a result of dedifferentiation of a well-differentiated papillary or follicular carcinoma. Medullary thyroid cancer (MTC) is derived from parafollicular or C cells which are included in the neuroendocrine tumor family; MTC may be a part of multiple endocrinological malignancy type II (MEN II) $[1-3]$.

In the United States, approximately 23,500 new DTC cases are diagnosed each year and its incidence has continuously increased in the last three decades all over the world except for a few countries (such as Norway and Sweden). Recent reports indicated that there were 3 - to 5-fold increases in incidence rates from 1980 to 1997 depending on age, gender, histological type of thyroid cancer, radiation exposure, geographical region and other factors. The highest increase in incidence was found in PTC [4]. Frequent use of sensitive diagnostic techniques such as high-resolution ultrasonography, computerized tomography, magnetic resonance or positron emission tomography may be responsible for incidental detection of thyroid tumors. Additionally, true increases in incidence rates of thyroid cancers can also be explained with increased environmental radiation and use of medical radiation, iodine intake, the Chernobyl disaster, carcinogens, environmental, ethnic and genetic factors or combinations of these factors [4-7].

The most frequent type of thyroid cancer is PTC constituting $75-85 \%$ of all cases. Multifocality, lymphatic or local spreading and lymph node metastases are characteristic features of PTC whereas distant metastases by hematogenous spreading are relatively uncommon. The overall 5 and 10year survival rates of PTC are approximately $97 \%$ and $93 \%$, respectively $[6,8,9]$. In most low risk patients with small tumors, no local or distant metastases and extrathyroidal infiltration, surgery and post-surgical radioiodine ablation therapy is usually adequate. Moreover, for PTC patients with $<1 \mathrm{~cm}$ tumor size, surgical treatment alone may be sufficient. Metastatic doses and repeated radioiodine therapy have been used for patients with lymph node or distant metastases and extrathyroidal soft tissue spreading [10-13]. PTCs are the predominant histological type in children with thyroid cancer and in patients with head-and-neck irradiation history. The clinical course of these patients is relatively worse because of the aggressive behavior of these tumor $[3,6,8]$. PTCs frequently have genetic alterations such as point mutations of $\mathrm{BRAF}$ and RAS genes and RET/PTC rearrangements. These genetic alterations are found in more than $70 \%$ of the patients and may have prognostic implications [14-17].

FTC is second most common thyroid malignancy and accounts for $10-15 \%$ of thyroid cancers $[6,8]$. FTC tends to metastasize to lung and bone via the bloodstream. Prognosis of FTC is worse than PTC especially in patients with distant metastases. The overall 5 and 10-year survival rates for follicular thyroid cancer are $91 \%$ and $85 \%$, respectively. Treatment strategy is thyroidectomy followed by ablative or metastatic doses of radioiodine therapy $[12,13,18,19]$. Approximately $50 \%$ of FTC patients have mutations in RAS family genes or PAX-PPAR $\gamma$ rearrangements $[14,20,21]$.

ATC is an uncommon, lethal malignancy of older adults. The mean survival time is usually less than 6 months from the time of diagnosis and this outcome is not altered by current treatments. Patency of the airway is critical for the patient's course due to aggressive local spreading of the primary tumor and airway obstruction is the primary cause of death in most patients [1].

Thyroid follicular cells trap iodine by a $\mathrm{Na}^{+} / \mathrm{I}^{-} \mathrm{Sym}-$ porter (NIS), which is an energy-dependent transport system regulated by thyroid stimulating hormone (TSH). Iodine is organified by thyroid peroxidase (TPO) at the apical surface of the thyroid cells and then conjugated to thyroglobulin ( $\mathrm{Tg}$ ). Iodine is also trapped and organified by DTC cells as in thyrocytes and this unique characteristic plays the most important role on treatment and diagnosis of DTC [22-24]. 131 Iodine $\left({ }^{131} \mathrm{I}\right)$ is a $\beta$ and $\gamma$ emitting radionuclide and chemically identical to the non-radioactive form of iodine. Radioiodine is an effective therapeutic and imaging agent for DTCs. Dedifferentiated, poorly differentiated and anaplastic thyroid tumor cell clones have lost the ability to trap iodine. Thus, radioiodine is not effective for detection and therapy of these tumors 
[25]. Non-radioiodine avid tumors have aggressive behavior and poor prognosis.

Whereas radioiodine is the primary therapeutic agent for DTC, clinical response of residual or recurrent tumor and distant metastasis is variable. Age, gender, tumor histological type, clinicopathological features, stage of the disease, presence of distant metastasis, ability to trap radioiodine and molecular genetic alterations may be responsible for the aggressive clinical course of the disease. Molecular profiling of he thyroid cancers is important for determination of prognosis, causes of treatment resistance and targeted therapy options especially in radioiodine refractory patients.

In recent years, knowledge about genetic aberrations in thyroid cancers has significantly increased. Accumulating data on the molecular biology of thyroid cancers can be an important avenue for diagnosis, classification and treatment of thyroid cancers. In this comprehensive review article, we update the data generated on molecular biology of thyroid cancers and discuss the translational aspects of thyroid cancer molecular biology.

\section{Genetic changes in thyroid cancer}

PTC and FTC are the most common types among all thyroid malignancies and the development of molecular markers for these tumors is very significant in terms of diagnosis, prognosis, treatment and follow up [26-28]. Four different gene mutations with significant effects on tumor prognosis and diagnosis have been identified. They are BRAF and RAS point mutations, and RET/PTC and PAX8/PPARc rearrangements.

\subsection{BRAF}

BRAF, a member of the RAF protein family, is a serine-threonine kinase. As RAS binds and activates BRAF, it is translocated to the cell membrane and directly associates with the MAPK signaling pathway [14]. BRAF phosphorylates and activates MEK, which in turn activates ERK and all the downstream effector molecules of MAPK. Activated ERK and ELK1 translocate to the nucleus and regulate transcription of genes involved in cell differentiation, proliferation, and survival (Fig. 1) [26,14]. The most common genetic changes in PTC include point mutations of BRAF which are observed in $35-70 \%$ of papillary thyroid carcinomas $[29,30]$. More than $95 \%$ of BRAF mutations detected in thyroid cancers are thymine to adenine transversions at position 1799 (T1799A) resulting in the substitution of valine by glutamate at residue 600 (V600E) (Table 1) [31]. This mutation causes constitutive activation of BRAF kinase and, thus, induction of the MAPK signaling pathway, which is responsible for thyroid tumorigenesis [14,31]. In small percentages of PTC, K601E point mutation, small deletions or insertion around codon 600 and AKAP9/BRAF rearrangement are also be observed [30]. There is a direct association between
BRAF mutation and aggressive clinical outcomes such as invasion, metastasis and relapse of PTC [32]. It has also been demonstrated that BRAF mutation is associated with loss of radioiodine avidity in recurrent PTC which cannot be cured [33]. Several studies demonstrated a close association between BRAF mutation and dedifferentiation of PTC [32-34]. All the rearrangements and mutations increase BRAF activity and cause continuous induction of the MAPK signaling pathway.

Effects of BRAF mutations on induction and dedifferentiation, in addition to its effects on tumor aggressiveness, were examined in a transgenic mice model with V600E BRAF. The results revealed that these transgenic animals had PTCs and showed invasion, a common property of aggressive tumors [35]. All these data suggest that mutations in BRAF can be used as a novel marker for the prognosis of thyroid cancer.

\subsection{RET/PTC rearrangements}

RET (rearranged during transfection), a proto-oncogene, encodes for a membrane-bound receptor tyrosine kinase and is highly expressed in calcitonin-producing parafollicular cells (C cells) in the thyroid gland (Table 1) [36]. The activation of the RET gene in follicular cells as a result of a chromosomal rearrangement called RET/PTC plays important roles especially in the pathogenesis of childhood PTCs and PTC arising from radiation exposure [36,37]. RET/PTC rearrangements are characterized by a fusion between the tyrosine kinase domain of the RET gene located on the $3^{\prime}$ and $5^{\prime}$ terminii of various partner genes [38]. Based on the partner genes, at least 10 different types of RET/PTC rearrangements have been identified. Of these, the most common types in PTC are RET/PTC1 and RET/PTC3 $[39,40]$. The partner genes for RET/PTC1 and RET/PTC3 are the coiled-coil domain containing gene 6, CCDC6 (also called H4/D10S170) and the nuclear receptor co-activator gene 4, NcoA4 (also called RFG/ELE1) genes, respectively $[36,41]$. Oncogenic activity of RET/PTC is related with the MAPK signaling cascade. In this cascade, RET/PTC first binds to adaptor proteins such as GRB2 and SOS and then activates RAS. Then, RAS activates RAF kinases such as BRAF and the downstream signaling cascade including MEK and ERK [42]. Although the exact role of RET/PTC at the early stage of thyroid tumorigenesis is unknown, a correlation between the presence of RET/PTC and a high growth rate of benign thyroid tumors has been found in a recent study [43]. Therefore, testing for RET/PTC rearrangements by different molecular approaches will be helpful for the diagnosis of thyroid cancer [44].

\subsection{The MAPK signaling pathway}

The mitogen-activated protein kinase (MAPK) pathway plays a major role in terms of regulating cellular events, such as proliferation, survival, and is also known to affect tumorigenesis. Genetic and epigenetic alteration of the RAS-RAF-MEK-MAPK-ERK pathway is the most 


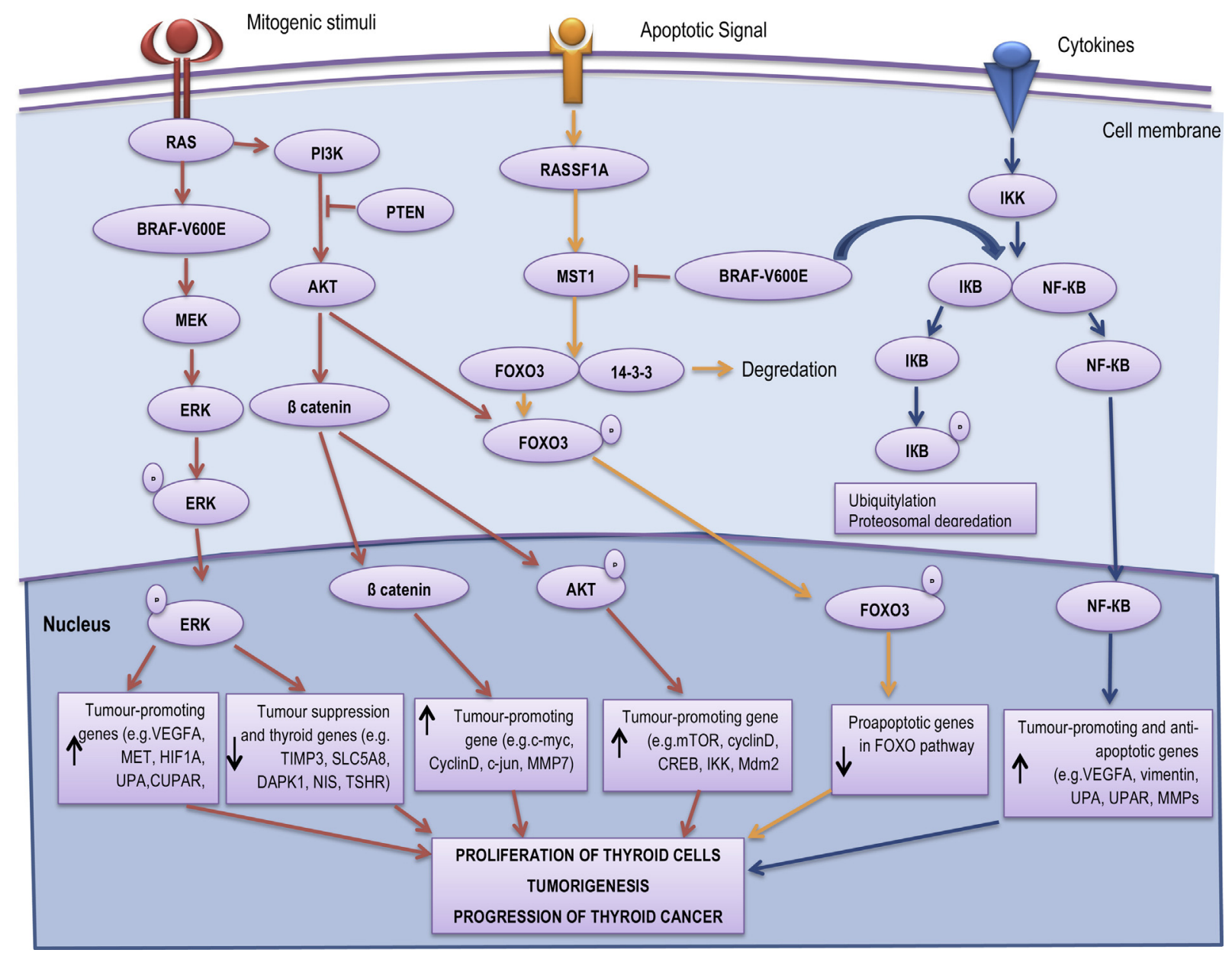

Fig. 1. The signaling pathways in thyroid cancers.

common, and was shown to highly affect thyroid cancer, particularly for PTC (Fig. 1) [45,34].

As mentioned earlier, the MAPK signaling pathway regulates cell proliferation, differentiation and survival by allowing the cells to respond to external stimuli by interaction of cellular tyrosine kinases (such as RET and G-protein-coupled receptors) with hormones, growth factors and cytokines [46]. The MAPK pathway also has a major role in human tumorigenesis. In thyroid cancer, RET/PTC rearrangements and point mutations in RAS and BRAF genes have been shown to activate the MAPK pathway [47-51]. Following the activation of the MAPK pathway, secondary molecular events occur, such as hypomethylation and genome-wide hypermethylation, which augment the tumorigenic activity of this pathway [52]. In addition, upregulation of several oncogenic proteins, such as chemokines $[53,54]$, nuclear factor $\kappa \mathrm{B}(\mathrm{NF}-\kappa \mathrm{B})$ [55], vascular endothelial growth factor A (VEGFA) [56], matrix metalloproteinases (MMPs) [53,55,57], MET [58,59], vimentin [60], prokineticin 1 (PROK1; also known as EG VEGF) [61], prohibitin [62], hypoxia-inducible factor $1 \alpha(\mathrm{HIF} 1 \alpha)$ [63], thrombospondin 1 (TSP1) [64], urokinase plasminogen activator (uPA) and its receptor (uPAR) $[65,66]$ and transforming growth factor $\beta 1$ (TGF $\beta 1$ ) [67,68] drive cancer cell growth, proliferation and survival, together with tumor angiogenesis, invasion and metastasis.

\subsection{The PI3K/AKT signaling pathway}

The phosphatidylinositol 3-kinase (PI3K)/Akt signaling pathway has major roles in several cellular events including growth, proliferation and apoptosis [69,70]. Activation of this pathway leads to tumorigenesis including thyroid carcinoma [71,72]. The role of the PI3K/AKT pathway on thyroid tumorigenesis was first revealed by the finding that Cowden's syndrome (which is caused by germline mutations of PTEN) was associated with follicular thyroid adenoma (FTA) and FTC [73]. Activation and increased expression of Akt has been shown to activate the PI3K/Akt pathway and lead to thyroid tumorigenesis (Fig. 1). FTCs have been shown to have higher levels of Akt activation as compared to papillary carcinoma and normal tissues $[74,75]$. Three types of Akt have been identified: Akt-1, Akt-2 and Akt-3. Activated Akt induces the signaling cascade by phosphorylating 
Table 1

Thyroid tumors with their characteristics and mutational profiles.

\begin{tabular}{|c|c|c|c|c|}
\hline Tumor type & $\begin{array}{l}\text { Prevalence (\% of } \\
\text { thyroid cancers) }\end{array}$ & 10 -Year survival $(\%)$ & $\begin{array}{l}\text { Mutations observed and their } \\
\text { prevalence }\end{array}$ & Effects of these mutations on tumor \\
\hline Papillary carcinoma & $80-85$ & $95-98 \%$ & $\begin{array}{l}\text { BRAF (V600E) 45\% } \\
\text { RET/PTC 20\% } \\
\text { RAS } 10 \% \\
\text { TRK <5\% }\end{array}$ & $\begin{array}{l}\text { Promoting tumorigenesis, invasion, } \\
\text { metastasis, recurrence and mortality }\end{array}$ \\
\hline Follicular carcinoma & $10-15$ & $90-95$ & $\begin{array}{l}\text { RAS } 45 \% \\
\text { PAX8-PPARy 35\% } \\
\text { PIK3CA }<10 \% \\
\text { PTEN }<10 \% \\
\text { BRAF (V600E) }<10 \%\end{array}$ & $\begin{array}{l}\text { Promoting tumorigenesis, invasion, } \\
\text { metastasis, recurrence and mortality }\end{array}$ \\
\hline Medullary carcinoma & $3-5$ & $60-80$ & $\begin{array}{l}\text { Familial forms of RET }>95 \% \\
\text { Sporadic RET } 50 \%\end{array}$ & \\
\hline $\begin{array}{l}\text { Poorly differentiated } \\
\text { carcinoma }\end{array}$ & $<2$ & 50 & $\begin{array}{l}\text { RAS35\% } \\
\text { BETA CATENIN 20\% } \\
\text { TP53 20\% } \\
\text { BRAF } 15 \% \\
\text { PIK3CA } 10 \% \\
\text { AKT } 10 \%\end{array}$ & $\begin{array}{l}\text { Promoting tumorigenesis and tumor } \\
\text { progression, invasion, metastasis, } \\
\text { recurrence and mortality }\end{array}$ \\
\hline Anaplastic carcinoma & $1-2$ & $<10$ & $\begin{array}{l}\text { TP53 70\% } \\
\text { BETA CATENIN 65\% } \\
\text { RAS } 55 \% \\
\text { BRAF } 20 \% \\
\text { PIK3CA } 20 \% \\
\text { PTEN <10 } \\
\text { AKT } 10 \%\end{array}$ & $\begin{array}{l}\text { Promoting tumorigenesis and tumor } \\
\text { progression, invasion, metastasis, } \\
\text { recurrence and mortality }\end{array}$ \\
\hline
\end{tabular}

downstream protein effectors. Upon activation of the pathway, cell proliferation is promoted and apoptosis is inhibited. Akt-1 and Akt-2 were shown to be the most important genes in thyroid cancer [76]. It was previously determined that mutations, or amplification and genomic copy gain of the PI3KCA gene, encoding the catalytic subunit of PI3K, occur in thyroid tumors [77-79]. Decreased expression or inactivation of the tumor suppressor gene product PTEN and activation by RAS oncogenes have also been described to activate the PI3K/Akt signaling pathway and play a role in thyroid tumorigenesis [78-80]. Combinations of some of these PI3K/Akt genetic alterations, as well as combinations of these alterations with BRAF mutation, were shown to be present in more aggressive thyroid tumors such as ATC [78]. Genetic alterations that activate both MAPK and PI3K/Akt pathways were shown to be present in most (81\%) ATC cases.

In a transgenic mouse model where a mutant thyroid hormone receptor $\beta$ gene (TR $\beta P V)$ was knocked-in, the PI3K/Akt pathway was shown to be activated following interaction of TR $\beta P V$ with the $p 85 \alpha$ regulatory subunit of PI3K, and spontaneous development of FTCs was observed [81,82]. Several human tumor studies proposed that activation and nuclear localization of Akt1 is involved in the invasiveness and metastasis of FTC induced by the PI3K/Akt pathway [83]. This proposal-was supported by the detection of Akt1 mutations in metastatic thyroid cancers [84]. On the other hand, excision of Akt1 was shown to delay and prevent tumor development, angiogenesis, and movement of FTC to distant sites in TR $\beta P V$ mice [85].

\section{5. $R A S$}

The family of RAS (an abbreviation of RAt sarcoma) oncogenes encodes $21 \mathrm{kDa}-\mathrm{G}$-proteins that transmit signals from the receptors on cell membrane to several types of targets in the cell controlling MAPK and PI3K signaling pathways in thyroid cancer $[86,87]$. There are three different RAS genes, known as HRAS, KRAS, and NRAS, that pass the signals from cell membrane receptors to their intracellular adaptor molecules (Fig. 1) [86,87]. RAS proteins exist as an active form with guanosine triphosphatase (GTPase) activity and an inactive form that is bound to guanosine diphosphate (GDP). Generally, point mutations in codons 12,13 , and 61 of the RAS oncogene are observed in thyroid cancer. While the point mutations in codons 12 and 13 result in elevated affinity for GTP, point mutation in codon 61 leads to repression of GTPase activity in autocatalysis [86-88]. All of these point mutations fix the RAS protein in activated states and, therefore, result in continuous stimulation of downstream targets of RAS. This, in turn, results in instability of the genome, induction of other mutations, and transformation into malignancy (Table 1) [89]. These mutations are seen at different frequencies in different types of thyroid cancers. While in PTC, RAS mutations were observed in approximately $10 \%$ of cases, in ATC and FTC this frequency is $10-20 \%$ and $40-50 \%$, respectively [90-93]. RAS mutation in PTC leads follicular variants, and also more encapsulation, and fewer metastases to lymph node $[94,95]$. In ATCs, RAS mutations are generally 
observed in tumors that develop microfollicular pattern [96].

Studies on RAS mutation in different types of thyroid cancer have shown that these mutations are observed in both malignant and benign types of tumors [97]. However, codon 61 point mutations have been especially reported to cause tumor progression in an aggressive manner [98,99]. Studies with transgenic mice demonstrated that RAS mutations resulted in carcinogenesis and hyperplasia in thyroid [100].

\subsection{PAX8/PPAR $\gamma$ rearrangement}

The PAX8 gene encodes a transcription factor required for the generation of thyroid follicular cells and tissue-specific gene expression in thyroid. The peroxisome proliferatoractivated receptor $\gamma$ (PPAR $\gamma$ ) gene is a member of the nuclear hormone receptor superfamily including retinoic acid, estrogen receptor, androgen receptor, and also thyroid hormone [101]. The PAX8/PPAR $\gamma$ rearrangement occurs as a result of genetic translocation between chromosomes 2 (exon 7,8 or 9) and 3 (exon 1), t(2;3)(q13;p25) [102]. Although the main mechanism is not yet clear, this fusion results in significant increases in expression of PAX8/PPAR $\gamma$ chimeric protein which inhibits the tumor suppressor activity of PPAR $\gamma$ [103-106]. Deregulation of PAX8 function, essential for differentiation of thyroid cells, and induction of some other genes, that are unrelated to wild type PAX8 or PPAR $\gamma$ genes, may be responsible for generation of thyroid cancer after this rearrangement [107,108]. Generally, PAX8/PPAR $\gamma$ rearrangement is seen in follicular thyroid carcinoma at $30-35 \%$ frequency (Table 1) $[109,110]$. In addition, most studies have shown that this rearrangement is also seen in follicular adenomas at $2-13 \%$ frequency, and in papillary carcinomas with follicular variants at $1-5 \%$ frequency [111-113]. Rarely, in 1 out of 42 follicular carcinomas, another type of gene rearrangement of PPAR $\gamma$ with CREB3L2 (CREB3L2/PPAR $\gamma$ ) was observed [114].

\section{7. $p 53$}

The p53 gene encodes a transcription factor that regulates vitally important cellular functions such as cell growth, proliferation, cell cycle, apoptosis and DNA repair [115]. Expression of p53, known as the guardian of the genome, is triggered when the cells are under stress conditions and cell cycle progression is inhibited. Damage to the DNA is then repaired or the cells undergo apoptosis [116]. However, point mutations that inactivate the tumor suppressor gene, TP53, are common events in the initiation of cancer. In thyroid tumors, loss of TP53 gene activity is observed at a later stage. p53 loss is generally observed in 15-30\% of poorly differentiated carcinomas, in 60-80\% of ATCs, and is extremely rare in DTCs (Table 1) [86,117-120]. p53 inactivation in thyroid cells has been shown to enhance tumor growth and also causes continuous loss of differentiation. In one study, it was observed that the progressive loss of differentiation in
ATC and poorly differentiated carcinomas is controlled by inactivation of the p53 gene $[121,122]$.

The first mouse model of ATC was recently generated based on information provided by research and patientderived genetic data. It is known that molecular changes that characterize ATC are: inactivation of the TP53 gene or activation of the PI3K cascade, RAS family members, or BRAF $[123,124]$. Mouse thyroid follicular cells were used in the study for which inactivation of the TP53 gene was combined with constitutive activation of the PI $3 \mathrm{~K}$ signaling cascade, via deletion of the PTEN tumor suppressor. The tumors developing in these mice were observed to closely resemble human ATCs, and they were shown to undergo glycolytic shift and consequently respond to glycolytic inhibitor therapy.

It was demonstrated that loss of p53 triggers dedifferentiation of thyroid tumors. PTC developed in transgenic mice with thyroid-specific RET/PTC rearrangements while crossing with $\mathrm{p} 53^{-1-}$ mice, the progeny was developed $[125,126]$. On the other hand, expression of thyroid specific genes was detected after introduction of wild-type p53 into ATC $[127,121]$.

It is known that p53 mutation is rarely found in thyroid cancer, mainly in undifferentiated tumors, and it is generally involved in the progress of advanced cancer. However, recently, there is evidence indicating that p53 mutation may also be effective in the early stages of thyroid cancer. In these tumors, various inactivating mechanisms acting on the protein and/or its signaling pathway may inhibit wild-type p53 activity [122]. It is assumed that p53 mutations may be an initiator in poorly differentiated or ATC; but it is a late event contributing to the development of transformed phenotype.

\subsection{WNT-beta catenin pathway}

Abnormal activation of the Wnt signaling pathway leads to the development of epithelial tumors. In recent years, the importance of the Wnt/ $\beta$-catenin pathway in the initiation of thyroid cancer has gained significance. This pathway plays a major role in tumor development and epithelial renewal. In thyroid tumors, the most frequent mutations are found in the scaffold proteins adenomatous polyposis coli (APC) and Axin, as well as in $\beta$-catenin (Fig. 1) [128].

Poorly differentiated and ATCs constitute additional genetic changes that are normally not found in welldifferentiated cancers. These changes represent late events, which may be involved in the initiation of tumor differentiation. One of these late events is the formation of mutations in the CTNNB1 gene, which encodes $\beta$-catenin, a cytoplasmic protein that has a role in cell adhesion and is known to be an important intermediate in the wingless (Wnt) signaling pathway $[129,130]$. Point mutations occur in exon 3 of the gene these mutations have been found in 66\% of ATCs and 25\% of poorly differentiated carcinomas, although not in DTCs (Table 1) [131,132].

The direct role of $\beta$-catenin in proliferation of undifferentiated thyroid tumor cells has been understood. However 
more studies should be undertaken to determine the role of $\beta$-catenin in the earlier stages of thyroid tumor progression. The use of in vivo models which have a constitutively active Wnt/ $\beta$-catenin pathway could help to understand the mechanism by which the Wnt pathway promotes tumor development in thyroid cancer.

\subsection{The NF- $\kappa B$ signaling pathway}

The NF-кB pathway is one of the main players in the regulation of inflammatory responses that are involved in induction of cancer [133]. There are significant increases in activity of NF- $\mathrm{KB}$ in thyroid cancer cells and tissues [134-136].

Inhibition of NF- $\mathrm{KB}$ protein synthesis with specific antisense oligonucleotides significantly decreased growth rate of undifferentiated carcinoma cells [136]. This decrease was related to suppressed expression of c-myc, a target for NF- $\kappa$ B118. NF- $\kappa$ B is a transcription factor that induces expression levels of different oncogenes and is upregulated by the MAPK pathway, RET/PTC, RAS and BRAF-V600E in thyroid cancers [137]. Recently, it was shown that proliferative and anti-apoptotic genes were regulated by the NF- $\mathrm{KB}$ signaling pathway in thyroid cancer $[137,138]$. The mechanism of BRAF-V600E induced increases in expression levels

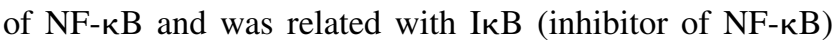
degradation in thyroid cancer cells [55].

\subsection{MicroRNAS}

Micro-RNAs (miRNAs) are small noncoding RNA genes composed of 21-25 nucleotides. They inhibit expression levels of genes at the transcriptional and posttranslational levels [139]. The aberrant expression of certain miRNAs can induce initiation and/or progression of human cancers [140]. The involvement of miRNAs in proliferation, differentiation and apoptosis have been defined and thus they could be used as biomarkers for diagnostic and therapeutic targets in many cancers including lung, pancreas, breast, and colorectal cancers in addition to thyroid cancers [141-144]. There are several reports displaying changes in miRNA profiles in thyroid cancers as compared to normal thyroid tissues $[143,144]$. Based on cellular origin and degree of tumor differentiation, different miRNAs are expressed in thyroid cancer [145]. Particularly miR-222, miR-221, and miR-146b have been found to be the most upregulated miRNAs in PTC. It was shown that miRNA-221 was also upregulated in unaffected thyroid tissue of several PTC patients, which was considered as an early event in carcinogenesis [146]. Moreover, the association between increased expression of miR-222, miR221, and miR-146b and pathological features of PTC has been examined and revealed that expression levels of these miRNAs were strongly related with extrathyroidal invasion. In addition, miR-146b was found to be highly expressed in PTC samples [147]. miR-222, miR-221, and miR-146b have been thought to play crucial roles in PTC initiation and development. The candidate targets of these miRNAs could be p27kip1, a cell cycle progression inhibitor, and KIT, a receptor tyrosine kinase that plays important roles in cell growth and differentiation [143,148]. Interestingly, high expression levels of miR-146b were found to be correlated with lower overall survival and with the development of drug resistance [149]. A recent study demonstrated that miR-146b could cause thyroid cancer development by regulating TGF- $\beta$ signaling, although the mechanisms of miR-146bmediated tumor behavior in PTC are largely unknown [150]. There were also significant increases in expression levels of miR-146b, miR-221, miR-222 and miR-135b in samples of PTC patients with extrathyroidal invasion [151].

There was an association between upregulation of miR-193b, miR-2861, miR-1202, and miR-451 and downregulation of miR-let-7i, miR-542-5p, miR-664, and miR-564 with lymph node metastasis [152]. Yu et al. identified the circulating miRNA profiles of PTC patients and showed that there were significant increases in serum let-7e, miR-151-5p, and miR-222 in PTC cases. An association with certain clinicopathological features such as tumor size and metastasis stage and expression levels of these miRNAs was also determined [153]. There were also significant downregulation of expression of certain miRNAs including miR-1, -191, -486, and -451 in PTC [154]. miR-1 silences CXCR4 which plays a major role in lymph node metastasis [155]. Therefore, its downregulation via miR-1 could be a potential strategy for overcoming lymph node metastasis. Recently several studies have reported the importance of miRNA deregulation in FTCs, although most of the studies have focused on PTCs. Weber et al. found four miRNAs, miR-192, -197, -328, and -346 , that seem to be specific for FTCs since they have not yet been associated with other thyroid cancer types [156]. The targets of miR-197 are ACVR1 and TSPAN3 genes while EFEMP2 is the target of miR-346 [156]. The EFEMP2 gene is thought to have tumor suppressor functions while the ACVR1 and TSPAN3 genes are involved in the control of cell growth and metastatic potential, respectively [157-159]. In vitro studies related with these miRNAs showed that their overexpression induced significant cell proliferation whereas inhibition caused growth arrest in human thyroid carcinoma follicular cells $[154,156]$.

In conclusion, miRNA expression profiles demonstrate differences between thyroid tumors and healthy tissues, primary tumors and metastatic tumors, and even between different regions of the same tumor. Therefore, miRNAs could be used as a novel marker for tumor diagnostic purposes.

\subsection{The HIFla pathway}

Hypoxia-inducible factor (HIF)- $1 \alpha$, through binding to HIF1 $\beta$ (known as ARNT), forms HIF1 transcription factor which triggers the expression of genes regulating tumor angiogenesis [160]. It was demonstrated by several groups that HIF1 $\alpha$ is expressed in thyroid tumors, such as ATC, and is not expressed in healthy thyroid tissues $[161,162]$. 
A significant increase in expression levels of HIF1 $\alpha$ in BHP10-3SC (mice) and human PTC tissue was determined [163]. HIF1 induces expression of VEGF, a growth factor, and MET, an oncogene, which are also upregulated in thyroid tumors as compared to normal thyroid tissues [162]. On the other hand, PI3K-AKT and MAPK increase expression of HIF1 in thyroid tumor $[161,164,165]$ while a mutation in BRAF (V600E) also affects expression levels of HIF1 $\alpha$ in papillary thyroid cancer [165]. Interestingly, inhibition of expression levels of HIF- $1 \alpha$ and HIF- $2 \alpha$ by GDC-0941 in four different thyroid tumor cells (BcPAP, WRO, FTC133, and 8505c) resulted in inhibition of VEGF secretion [166]. Koperek et al. demonstrated that tumor hypoxia is involved in the development of regional metastases in MTC [167]. All these results suggest that HIF1 can be used as a diagnostic and even prognostic marker for thyroid tumors. More importantly, targeting HIF1 with special inhibitors could be a novel approach for effective treatment of thyroid cancers since it induces angiogenesis and metastasis of thyroid tumors.

\subsection{Aberrant methylation}

Changes in methylation status of the genome are hallmarks of cancers including thyroid cancer [168]. Hypermethylation of many tumor suppressor genes was determined for thyroid cancer by several groups [168]. Aberrant methylation results in downregulation of the genes as it occurs in regulatory sequences. It was determined that the BRAFV600E mutation is associated with hypermethylation of various tumor suppressor genes, such as death-associated protein kinase 1 (DAPK1), retinoic acid receptor- $\beta$ (RARB), tissue inhibitor of metalloproteinases 3 (TIMP3) and SLC5A8 [169]. Interestingly, Hou et al. demonstrated that BRAFV600E signaling induced changes in methylation, both hypermethylation and hypomethylation, and methylation regulates high numbers of genes involved in the control of vital important cellular functions in PTC cells [170]. An association between BRAF mutations and aberrant methylation of DNA repair genes, especially the hMLH1 gene was detected which also determines the aggressiveness of PTC $[170,171]$. These results revealed that changes in methylation levels resulting from BRAF-V600E are important in induction of thyroid cancers.

Methylation of PTEN in regulatory sequences resulting in downregulation of expression of PTEN is also observed in FTC [172-174]. Methylation of PTEN is related with changes in the PI3K-AKT pathway, mutations in RAS, and mutations and amplifications in PIK3CA in thyroid tumors [171]. It was shown that increased activity of the PI3K-AKT pathway induces changes in methylation and downregulates PTEN [172].

Thyroid molecules including NIS, TSH, Tg, TPO receptors, and pendrin are generally lost in thyroid tumors because of aberrant methylation. This aberrant methylation is regulated by the BRAF mutation-promoted MAP kinase signaling pathway and inhibition of MAP kinase by specific chemicals can reverse this event [168].

Although genetic problems were clearly identified for many thyroid cancers, around 30-35\% of DTCs could not be explained by genetic problems. This indicates that changes in epigenetics should be further investigated.

\section{Molecular targets in histopathological diagnosis and classification of thyroid cancer}

Histopathological examination is essential in current clinical practice to classify histological subtypes or variants and to distinguish malign thyroid tumors from benign ones. The histopathological classification recommended by WHO has been used for distinguishing thyroid tumor types in postoperative thyroidectomy materials and the Bethesda system has been used for classifying thyroid cytopathology of fine needle aspiration biopsy (FNAB) samples [175]. For many thyroid tumor types such as follicular patterned tumors (follicular adenoma, FTC, minimally invasive FTC and follicular variant of PTC) and several variants of PTC, histological or cytological criteria are subjective. Thus it is possible to have diagnostic errors, problems and interobserver variability. Furthermore, reliable prognostic markers are still insufficient. The most prominent interobserver variability has been reported in follicular-patterned tumors [175-178]. Final agreement for reported criteria such as capsular or vascular invasion and differential diagnosis of follicular adenoma and carcinoma is very low (27, 20 and $37 \%$, respectively) [177]. Some disagreements between pathologists have also been reported for classification of histological variants of PTC and FNAB [175-178].

Morphological and biological characteristics of FTA and FTCs are very similar and thus it may be impossible to make definitive differential diagnosis by FNAB sampling. Therefore, $10-40 \%$ of all FNABs are reported as indeterminate for malignancy. Many immunohistological markers have been improved for more accurate differential diagnosis of thyroid tumors. However they have limited use in routine practice because many of them show overlap between some subtypes of thyroid cancer [179].

Molecular markers hold promise to improve preoperative diagnosis of thyroid cancer. Diagnostic use of gene mutations (BRAF, RAS, PET/PTC, PAX8/PPAR $\gamma$ ), alterations in gene expression profile and miRNA signatures have several advantages in differential diagnosis of thyroid tumors. Identifying specific molecular or genetical alterations offers not only the possibility of distinguishing benign and malign tumors and to classify thyroid malignancies but also to make prognostic stratification. Diagnostic use of mutational markers as single gene analyses or a panel of mutations may help to improve the accuracy of FNAB. RET/PTC, BRAF, NTRK, RAS and PAX8-PPAR $\gamma$ mutations have been frequently explored for diagnosis of thyroid cancer. Gene expression profiling and microRNA studies have identified a variety 
of potential molecular markers to help distinguish benign from malignant thyroid neoplasms especially for nodules that are classified as indeterminate for malignancy by FNAB $[36,37,45,34,90-93,109-113,178,180-182]$. The inability to exclude malignancy in these nodules may often lead to unnecessary surgery or two step surgical procedures. More accurate preoperative diagnosis significantly reduces the frequency of unnecessary surgery and thus patient morbidity.

PTCs are a histologically heterogeneous group of tumors that are classified as classical, follicular, tall-cell, columnar-cell, cribriform-cell, onchocytic (hurtle cell), diffuse sclerosing and solid variants. The role of molecular diagnostic markers on classification of PTC is uncertain. The vast majority of PTCs are characterized by mutations or rearrangements along the MAPK pathway like RET/PTC rearrangements and BRAF mutations.

The prevalence of RET/PTC rearrangements in PTC is variable $(0-87 \%)$ depending on histological subtype, age, geographical factors, radiation exposure and detection methods but such rearrangements represent most of the cases with no or very low incidence in FTC and ATCs. Initial reports suggested that RET/PTC was specific for PTC [183,184] but later it was also found in some benign lesions [185,186] and diseases such as Hashimato disease [187]. According to these results, RET/PTC is not a specific PTC marker. However, recent studies suggested that RET rearrangements in benign thyroid nodules could be associated with a higher growth rate of the nodule, thus, RET/PTC positive benign nodules must be subjected to careful follow-up [188-190]. RET/PTC1 and RET/PTC3 are the most common isoforms of RET/PTC, with the first predominant in the classical type of PTC and the second predominant in the solid variant of PTC [180,191]. RET/PTC3 is also predominant among radiationinduced PTCs such as post-Chernobyl PTCs and has more aggressive behavior [192,193]. However, there was no significant correlation found in the occurrence of RET/PTC in patients with and without history of medical radiation [194]. Presence of RET/PTC activation may be a complementary approach in patients reported to have indeterminate cytology by FNAB and with borderline histological features of malignancy in microscopic papillary foci of thyroid nodules [195]. Most studies demonstrated that the sensitivity of molecular assays has improved by combined detection of BRAF and RET/PTC. An increased sensitivity from about 42.3-69\% to 56.4-78\% has been reported [196-198].

The BRAF point mutation is the most common mutation in PTC (35-70\%) and has recently been reported to be associated with poor prognostic features like extrathyroidal soft tissue infiltration, lymph node metastasis, disease aggressiveness, tumor recurrence, loss of radioiodine avidity and, thus, resistance to annual therapeutic methods [29-34,199,200]. Additionally, the BRAF mutation occurs most commonly in aggressive subtypes of PTC [178,201]. Loss of NIS and TPO are early markers of dedifferentiation and they are also responsible for poor prognosis in BRAF positive PTCs [202]. According to these results, the BRAF mutation is a potential independent prognostic molecular marker for PTC. More extensive surgery, higher doses of radioiodine, lower levels of suppression of TSH and closer monitoring during the follow-up period will be helpful for disease control in patients with BRAF positive PTC.

Because of its high prevalence and specificity to PTC and PTC-derived dedifferentiated tumors, screening the BRAF mutations in FNAB samples may be useful for preoperative diagnosis [203,204]. Recent studies reported that the BRAF mutation is a highly accurate marker of malignancy for thyroid nodules sampled by FNAB [205-209]. However, the most frequent diagnostic problems in FNAB samples are indeterminate follicular tumors and suspicion of malignancy according to the Bethesda system. The diagnostic potential of the BRAF mutation is relatively low for indeterminate follicular neoplasms [210]. Additionally, BRAF mutations demonstrate a high geographical variability and local frequency must be taken into consideration for evaluation of the results. Despite these factors, recent studies reported that 580 of 581 BRAF-positive nodules were PTC and the false positive rate of BRAF mutational analysis was only $0.2 \%$ $[26,28]$. Moreover $15-40 \%$ of BRAF-positive FNAB samples were indeterminate by cytology. These reports indicate that BRAF analysis on FNAB samples is a reliable diagnostic marker for PTC. Despite high specificity, analyses of BRAF alone in FNAB samples may miss some thyroid cancers that are negative for BRAF mutation.

In FTC, RAS mutations and a fusion oncogene between PAX8 and PPAR $\gamma$ have been more frequently observed than follicular adenoma. Frequency of RAS mutation, the second most common mutation after BRAF, is about $40-50 \%$ in FTCs and $10 \%$ in PTCs (follicular variants) [90-93]. The positive predictive value of RAS mutation positivity in FNAB samples for thyroid cancer is about 74-87\%. Detection of the RAS mutation is associated with an $87-100 \%$ probability of malignancy [28]. Most importantly, RAS-positive thyroid cancers are FTC and the follicular variant of PTC which may cause false negative results in cytological evaluations. These results suggest that the diagnostic value of RAS mutation in FNAB samples is high for DTCs. Total thyroidectomy has been suggested as the initial surgical procedure in patients with thyroid nodules that are positive for the RAS mutation by FNAB due to the high preoperative probability of cancer [32]. PAX8/PPAR $\gamma$ rearrangement is characteristically seen in FTCs and it may be used as a diagnostic marker. However, PAX8/PPAR $\gamma$ mutation is rarely observed in some follicular adenomas. Detection of the PAX8/PPAR $\gamma$ mutation should alert the pathologist to re-examination for histological features of follicular carcinoma such as vascular or capsular invasion $[26,28]$.

Several studies reported that the most effective diagnostic utility can be achieved by a panel of mutations in FNAB samples. Ohori et al. suggested a panel of biomarkers including BRAF-RAS gene mutations and RET/PTC-PAX8-PPAR $\gamma$ gene translocations to optimize FNAB results [211]. This panel includes some of the most frequent and specific 
molecular markers identified to date for thyroid cancer and may be used in routine practice. TRK rearrangements may also be added to this panel. Presence of BRAF, RAS, RET/PTC, PAX8-PPAR $\gamma$ and TRK in FNAB samples correlated with malignancy in $97 \%$ of cases $[196,197,212]$. Therefore, detection of any mutation of this panel is a strong predictor for thyroid cancer. The revised American Thyroid Association's (ATA) Management Guideline recommended using a mutational panel for nodules classified as indeterminate by FNAB [213]. Nodules with indeterminate cytology have a 5-10\% probability for malignancy and usually undergo repeated FNAB according to classical follow-up protocols [175,214]. Analysis of a panel of mutations is particularly useful for management of patients with indeterminate thyroid nodule that are at the low risk category for thyroid cancer. The most common mutations in these nodules are RAS, BRAF and PAX8-PPAR $\gamma$ rearrangement. Detection of these molecular alterations indicates a high risk category for malignancy. Thus, the patient may be referred to surgery without repeated FNAB. Conversely, the risk of cancer is about $0-7 \%$ in thyroid nodules those are negative for all these mutations [196,211]. In this lowest risk group, follow-up is sufficient without the necessity of surgical intervention. As has been recommended in the revised ATA guideline, the use of mutational analyses in FNAB samples is useful for pre-operative evaluation and clinical management of thyroid nodules, especially those which are indeterminant.

In addition to somatic mutations, changes in gene expression profiles detected by microarray techniques and some miRNA markers have been identified and may be of potential use for diagnostic purposes in thyroid cancer $[26,32,178]$. Upregulation or aberrant expression of HMGA2, MET, TPO, TIMP1, DPP4, TFF3, SERPINA1, TIMP1, FN1, TGFA, CRABP1, FCGBP, EPS8 and PROS1 genes have been detected in malignant thyroid tumors [215-220]. Diagnostic use of expression levels and profiles of multiple genes have been tested and it is reported that the sensitivity and specificity of these techniques in differential diagnosis of malignant and benign thyroid nodules were $92 \%$ and $84 \%$, respectively [221]. Mathur et al. have explored the diagnostic utility of combined use of mutational analysis, gene expression profiling and classical cytological evaluation of FNAB samples [222]. This study suggested that combined use of these molecular analyses has improved diagnostic accuracy of FNABs. However, no reliable single marker was identified and diagnostic use of micro-array technology in routine practice on FNAB samples is currently not only feasible but also cost-effective.

There are several studies reporting overexpression of miRNAs including miR-222, miR-221, and miR-146b in PTC and these miRNAs may be of diagnostic potential [143-151]. In a recent study, a panel of seven miRNAs was used in thyroid FNAB samples [223]. When presence of up-regulation of three or more of these miRNAs including miR-222, miR-221, miR-146b, miR-224, miR-155, miR-187 and miR-155 was accepted as a predictor of thyroid cancer, diagnostic accuracy of FNAB was 98\% [223]. This result suggests that diagnostic use of miRNA analysis is feasible and improves diagnostic accuracy of thyroid FNABs in preoperative evaluation. However, their clinical use in routine practice requires additional studies.

\section{Targeting molecular pathways for the treatment of thyroid cancer}

Currently, novel therapy regimens for thyroid cancer have been developed using therapeutic targets such as BRAF, RET, MEK and AKT, and tested at different stages of clinical trials. The results of these clinical studies give information on therapeutic efficacy of these therapies and their potential use alone or in combination with other treatment strategies for thyroid cancer (Table 2). These novel therapeutic regimens will be useful particularly for the treatment of MTC, non-radioiodine avid DTC's, and aggressive types of thyroid cancer, including poorly differentiated and ATC's.

\subsection{Targeting BRAF}

Due to the high frequency of BRAF mutations in thyroid cancers and its association with tumor dedifferentiation and resistance to radioiodine therapy, several BRAF inhibitors have been recognized and tested as potential therapeutic agents. Moreover, since BRAF takes place downstream of RET and RAS in the signaling cascade, BRAF inhibitors were suggested to be potentially effective in tumors with other mutations that affect the signaling pathway upstream of BRAF.

A promising BRAF inhibitors is BAY 43-9006, a multikinase inhibitor, which effectively inhibits wild-type BRAF and the kinase activity of mutant V600E BRAF [224]. This agent has also been shown to have potent activity against VEGFR2, VEGFR-3, FLT-3, c-KIT and PDGFR $\beta$ kinases [225]. In a study, oral administration of BAY 43-9006 resulted in a strong antitumor effect in xenograft models of various types of cancer. The results demonstrated that this effect was through inhibition of MAPK signaling and angiogenesis [225]. In preclinical studies, BAY 43-9006 has been shown to hinder BRAF signaling and inhibit the growth of all thyroid cancer cell lines carrying the mutant $B R A F$ [226]. It was also shown to impair the growth of the ATC cell line xenografts in nude mice [228]. Recently, the therapeutic effects of BAY 43-9006 on cells carrying the activated forms of RET and RET/PTC were also demonstrated [227].

BAY 43-9006, another BRAF inhibitor, has also been tested in clinical studies for several types of cancer, including thyroid cancer. In the trial of patients with progressive papillary carcinoma, some patients had minimal or partial response [228,229].

The efficiency of AAL-81 and LBT-613, other inhibitors of RAF kinases, have been tested in thyroid cells in preclinical studies [230]. Both agents were determined to inhibit MAPK 
Table 2

Completed/ongoing phase I/II trials with molecular therapy and their published response rates for thyroid cancers (NOR: no objective responses).

\begin{tabular}{|c|c|c|c|c|}
\hline Agents & $\begin{array}{l}\text { Completed/ongoing } \\
\text { phase I, II, III trial }\end{array}$ & Molecular target & Response rates & Refs. \\
\hline Everolimus & Phase II completed & mTOR inhibitor & $5 \%$ & [254] \\
\hline Lenvatinib & Phase II completed & $\begin{array}{l}\text { Tyrosine kinase inhibitor targeting VEGFR1-3, } \\
\text { FGFR1-4, RET, KIT and PDGFR } \beta\end{array}$ & $50 \%$ & [255] \\
\hline Gefitinib & Phase II completed & Inhibition of EGFR & NOR & [256] \\
\hline Depsipeptide (DEP) & Phase II completed & Histone deacetylase inhibition & NOR & [257] \\
\hline Vorinostat & Phase II completed & Histone deacetylase inhibition & NOR & [258] \\
\hline Axitinib & Phase II completed & Inhibition of VEGFR & $30 \%$ & [259] \\
\hline Sorafenib & Phase II completed & $\begin{array}{l}\text { Inhibiting Raf kinase, VEGFR, PDGFR, and RET } \\
\text { tyrosine kinases }\end{array}$ & $23 \%$ & [260] \\
\hline Suberoylanilide hydroxamic acid & Phase I completed & $\begin{array}{l}\text { Inhibits histone deacetylase activity in } \\
\text { peripheral-blood mononuclear cells (PBMNCs) }\end{array}$ & $30 \%$ & [261] \\
\hline Motesanib & Phase II completed & Inhibitor of VEGF R, PDGFR and KIT & $14 \%$ & [262] \\
\hline Thalidomide & Phase II completed & $\begin{array}{l}\text { Inhibit angiogenesis induced by bFGF or VEGF } \\
\text { in vivo }\end{array}$ & $18 \%$ & [263] \\
\hline Pazopanib & Phase II completed & Tyrosine-kinase inhibitory & $49 \%$ & [264] \\
\hline XL-184 & Phase I completed & MET, VEGFR-2 and RET kinase inhibitor & $26 \%$ & {$[265]$} \\
\hline XL-184 & Phase II completed & MET, VEGFR-2 and RET kinase inhibitor & $21 \%$ & [265] \\
\hline Imatinib & Phase II completed & Tyrosine-kinase inhibitor & NOR & [266] \\
\hline Celecoxib & Phase II completed & Selectively COX-2 inhibiting & $3 \%$ & [267] \\
\hline Combretastatin A4 phosphate & Phase II completed & Tubulin-binding vascular disrupting agent & NOR & [268] \\
\hline Sunitinib & Phase II completed & Inhibitory activity against RET, VEGFR, and PDGFR & $13 \%$ & [269] \\
\hline Selumetinib (AZD6244) & Phase II completed & RAF/MEK/ERK (MAPK) signaling & $3 \%$ & [270] \\
\hline Vandetanib & Phase III completed & Inhibitor of RET kinase, VEGFR and EGFR signaling & $37 \%$ & [271] \\
\hline Vandetanib & Phase II completed & Inhibitor of RET kinase, VEGFR and EGFR signaling & $20 \%$ & [272] \\
\hline Lenalidomide & Phase II completed & Inhibit tumor necrosis factor production & $22 \%$ & [273] \\
\hline Cabozantinib & Phase III completed & $\begin{array}{l}\text { Tyrosine kinase inhibitor (TKI) of MET, VEGFR2, } \\
\text { RET, MTC }\end{array}$ & $28 \%$ & [274] \\
\hline Thyrotropin & Phase I/II completed & $131 \mathrm{I}$ uptake and $\mathrm{Tg}$ release & NOR & {$[275]$} \\
\hline Fosbretabulin & Phase I completed & Tubulin inhibitory & NOR & [276] \\
\hline Romidepsin & Phase I/II completed & Histone deacetylase inhibition & NOR & [277] \\
\hline Doxorubicin and interferon $\alpha$ & Phase II completed & Inhibits the enzyme topoisomerase II & $6 \%$ & [278] \\
\hline Rosiglitazone & Phase II completed & $\operatorname{PPAR} \gamma$ & $25 \%$ & [279] \\
\hline Cisplatin & Phase II completed & Microtubulin inhibitor & NOR & [264] \\
\hline Decitabine & Phase II Ongoing & Inhibiting DNA methyltransferase & No study results posted yet & [264] \\
\hline Temsirolimus + sorafenib & Phase II Ongoing & $\begin{array}{l}\text { Inhibiting Raf kinase, VEGFR, PDGFR, RET tyrosine } \\
\text { kinases, mTOR }\end{array}$ & No study results posted yet & {$[264]$} \\
\hline Nintedanib (BIBF1120) & Phase II Ongoing & Inhibits receptors of VEGF, FGF and PDGF & No study results posted yet & [264] \\
\hline Pazopanib hydrochloride & Phase II Ongoing & $\begin{array}{l}\text { Tyrosine kinase inhibitor of VEGFR-1, VEGFR-2, } \\
\text { VEGFR-3, PDGFR-a/ } \beta \text {, and c-kit }\end{array}$ & No study results posted yet & [264] \\
\hline Motesanib & Phase II completed & Inhibits VEGF & $14 \%$ & [262] \\
\hline
\end{tabular}

signaling and growth of human thyroid tumor cell lines and rat thyroid cells carrying the V600E BRAF and RET/PTC1 mutations. The growth of BRAF mutant tumor xenografts in nude mice was also shown to be suppressed [231].

Potential therapeutic targets along the MAPK pathway are also found downstream of BRAF. A non-ATP competitive MEK inhibitor has been designated as CI-1040, and it was shown to inhibit the growth of BRAF mutant xenografts derived from various tumor types [232]. This study has also progressed to clinical trials.

\subsection{Targeting RET mutations and RET/PTC}

Activated RET kinase has been identified as a target by several small-molecule tyrosine kinase inhibitors in preclinical and clinical studies. ZD6474 is an orally active low molecular weight receptor tyrosine kinase inhibitor, which was shown to inhibit VEGFR-2 and block RET tyrosine kinase [233]. ZD6474 was demonstrated to block phosphorylation and signaling from RET/PTC3 in vitro. In that way, the growth of human papillary carcinoma cell lines harboring RET/PTC1 and RET/PTC3-transformed fibroblasts was arrested in nude mice [234,235].

In a clinical trial with metastatic familial MTC patients, ZD6474 therapy was reported to give some evidence of response [232]. Currently, a multi-center phase II double blinded study is being conducted to compare the efficiency of ZD6474 (ZACTIMA $^{\text {TM }}$, AstraZeneca Pharmaceuticals, DE, USA) versus placebo in patients with familial and sporadic MTC.

The antitumor activity of ZD6474 was suggested to be due to a combination of antiangiogenic activity mediated by 
blocking VEGFR and anti-RET activity of the agent. Therefore it is important to explore whether the presence of the RET mutation and its type affect the extent of the therapeutic response to ZD6474.

In preclinical studies, it was shown that ZD6474 can inhibit all the mutated variants of RET except for the V804L and V804M mutations [235]. V804 corresponds to the gatekeeper residues of PDGFR, c-KIT, ABL, and EGFR kinases, and mutations at these residues result in resistance to various inhibitors [236]. These results suggest that RET V804L and V804M mutations in medullary carcinomas may show primary resistance to ZD6474 [235].

A multikinase inhibitor SU12248 (Sunitinib) has been demonstrated to effectively block signaling from RET/PTC kinase. Sunitinib was also tested in Phase II clinical trial in radioiodine-refractory, unresectable DTC [237]. Additionally, in preclinical studies, the pyrazolopyrimidine compounds PP1 and PP2, two small-molecule tyrosine kinase inhibitors, have been shown to effectively inhibit RET/PTC signaling in vivo and abolish its oncogenic effects in experimental animals $[238,239]$.

\subsection{Targeting $R A S$}

Point mutations of RAS occur in both benign and malignant thyroid tumors. In PTCs, RAS mutations are found at relatively low frequencies, in approximately $10 \%$ of tumors. In follicular thyroid carcinomas, $40-50 \%$ of tumors carry $R A S$ mutations $[87,91,96]$, which may correlate with poor prognosis and tumor dedifferentiation [97,240]. RAS mutations may influence tumor dedifferentiation, as they are found with high frequency in ATCs. In vitro studies have provided evidence that the mutant RAS affects chromosomal stability [241,242]. Active RAS may induce thyroid tumorigenesis through the classic MAP kinase pathway or through interaction with the PI3K/Akt pathway. RAS mutations, however, are not specific for thyroid tumors, they can also occur in benign follicular adenomas.

\subsection{Targeting PI3K}

Previous studies have shown that activation of PI3K signaling is a common feature of many cancers including thyroid cancer [243]. Particularly, FTCs have been identified to have greater levels of Akt activation as compared to PTCs $[74,75]$. Genetic changes that activate the MAPK and PI3K/Akt pathways were shown to be present in most (81\%) ATC cases. Since both the MAP kinase and PI3K pathways are involved in the pathogenesis of ATC, targeting multiple signaling pathways may be a valuable therapeutic approach for thyroid cancer. Downstream signaling relay molecules such as BRAF, AKT, MEK and mTOR are examples of therapeutic targets that are being actively tested for the treatment of thyroid cancer [27]. In a recent study, the activity of the PI3K inhibitor GDC-0941 was assessed on hypoxiainducible-factor-1 (HIF-1), a transcription factor regulated by PI3K, for its metastatic behavior of thyroid cancer cells both in vitro and in vivo [164]. GDC-0941 has been shown to inhibit HIF- $1 \alpha$ and HIF- $2 \alpha$ expression, and HIF activity in thyroid carcinoma cells. In vivo, GDC-0941 has been demonstrated to decrease HIF- $1 \alpha$ expression in FTC xenografts, and reduce FTC tumor growth and metastatic lung colonization.

In a transgenic mouse model where a mutant thyroid hormone receptor $\beta$ gene (TR $\beta P V$ ) was knocked-in, the activation of the PI3K/Akt pathway was determined following the interaction of TR $\beta P V$ with the $p 85 \alpha$ regulatory subunit of PI3K, and spontaneous development of FTCs was observed [81,82]. Several human tumor studies proposed that activation and nuclear localization of Akt1 is involved in the invasiveness and metastatic behavior of FTC triggered by the PI3K/Akt pathway [75]. This result was supported by the detection of Akt1 mutations in metastatic thyroid cancers [84]. On the other hand, excision of Akt1 was shown to delay and prevent tumor development, angiogenesis, and movement of FTC to distant sites in TR $\beta P V$ mice [85]. In another study it was shown that treatment with LY294002, a PI3K inhibitor, prevents tumor development [244]. Several drugs have been developed to target the PI3K/Akt pathway, and their efficiency for the treatment of cancer is currently assessed in various clinical studies [245].

\subsection{Targeting PPAR}

To date, there is no definite evidence that PAX8/PPR $y$ rearrangement could be a sign of outcome in FTCs. Therefore, its use as a novel therapeutic target for FTC has been uncertain. However, a number of approved, well-tolerated, orally administered regulators of the PPAR $\gamma$ pathway are available, and are used in the treatment of type 2 diabetes. Currently, some clinical trials are ongoing with PPAR $\gamma$ agonists, alone or in combination with other conventional chemotherapeutic agents [246].

\subsection{Targeting $N F-\kappa B$}

The NF- $\mathrm{kB}$ pathway has a significant role in the regulation of inflammatory responses that are linked to oncogenesis [247], and increased NF-кB activation has been well documented in thyroid cancer cell lines [134-136]. In one study, it was shown that concurrent suppression of the NF- $\mathrm{kB}$ and MEK-ERK pathways through application of NF- $\mathrm{B}$ and MEK inhibitors repressed the proliferation of thyroid cancer cells carrying a BRAF-V600E mutation [248].

\subsection{Targeting epigenetic mechanisms}

Epigenetic alterations in thyroid tumors include changes that occur in DNA methylation patterns in the $\mathrm{CpG}$ islands of promoters of genes important in normal thyrocyte function and increased promoter methylation by DNA methyltransferases (DNMTs) causing gene silencing and dedifferentiation $[249,250]$. Studies on how posttranslational 
modification of histones may influence cancer have recently gained significance. The nucleosome consists of $147 \mathrm{bp}$ of DNA wrapped around an octamer of four core histone proteins (H2A, H2B, H3, and H4) [251]. Methylation, acetylation, phosphorylation, and ubiquitination are included in histone modifications that synergistically act with DNA promoter methylation to regulate gene silencing [252]. It is believed that epigenetic drug targets will play a more significant role in cancer treatment in the near future.

DNMT inhibitors such as $5^{\prime}$-azadeoxycytidine have been tested as "redifferentiation" agents, which allow tumors to regain their sensitivity to conventional radioactive iodine therapy [253]. A summary of ongoing or completed trials of treatment of thyroid cancers with molecular therapy is presented in Table 2.

\section{Current challenges and future venues for research in molecular therapy of thyroid cancers}

In the near future, increased access to array-type and next generation sequencing technologies will provide significant progress in our understanding of the molecular biology of thyroid cancers. Novel information including new mutations, genes and/or signaling pathways that are involved in initiation or progression of thyroid cancers may be an important avenue for diagnosis and prognosis of thyroid cancers. Therefore, determination of nucleotide sequences of genes, rearrangements and expression levels of the genes should become common diagnostic tools.

Targeting certain molecules involved in initiation and progression of thyroid cancers will also be an important research area. However, it is vital to determine whether the genetic differences observed in thyroid cancers correlate with the therapeutic response to specific inhibitors. Acquired and intrinsic drug resistance mechanisms and reversal of drug resistance are also important considerations for a complete cure.

On the other hand, environmental factors and sporadic conditions that induce thyroid cancer need to be addressed in order to clarify the increasing rates of thyroid cancers in various parts of the world in the last three decades. Overcoming these challenges will provide better prevention, diagnosis and therapy of thyroid cancers.

\section{Conclusion and future directions}

The contribution of multiple signaling pathways in the development of aggressive thyroid cancer suggests that it may be necessary to target them simultaneously for successful treatment. Indeed, clinical trials undertaken with single kinase inhibitors in thyroid cancer have generally shown only partial responses. Recently, various preclinical studies testing the combination of MEK or BRAF-V600E inhibitors with AKT, PI3K, or mTOR inhibitors demonstrated that they inhibit proliferation and induce apoptosis of thyroid cancer cells synergistically [280-282].

Novel and promising treatment strategies for thyroid cancers are based on molecular targeting [283]. New smallmolecule protein-kinase inhibitors including axitinib [259], sorafenib [260,284,285], motesanib [262] and pazopanib [264] have shown promise in clinical trials on thyroid cancer. PLX4032 (also known as vemurafenib), a BRAF-V600Especific inhibitor, has been recently approved by the FDA for the treatment of BRAFV600E-positive melanoma [286].

Targeting multiple signaling pathways in order to restore radioiodine avidity can be considered as another promising area of translational research on thyroid cancer. It was recently demonstrated that simultaneous inhibition of the MAPK, PI3K-AKT and histone deacetylase pathways could stimulate the expression of thyroid iodide-handling genes in thyroid cancer cells as compared to inhibition of one pathway alone [287].

In conclusion, remarkable progress has been made in understanding the molecular biology of thyroid cancer in recent years. This understanding of the molecular pathogenesis of thyroid tumorigenesis has now opened great opportunities for the development of novel molecular-based approaches for the effective management of the diagnostic and therapeutic obstacles of thyroid cancer.

\section{Reviewers}

Youssef Zeidan, M.D., Ph.D., Stanford Cancer Center, 875 Blake Wilbur Drive, Standford, CA 94305, United States.

Jingdong Qin, Ph.D., University of Chicago, 5841 S Maryland Avenue, Chicago, IL 60637, United States.

Vineet Gupta, Ph.D. MD, Anderson Cancer Center, Clinical Cancer Department.

Pengfei Song, PhD. St. John's University.

Dr. Ali Ugur Ural, M.D., Professor, Bayındır Hospital, Department of Hematology.

Dr. Guray Saydam, M.D., Professor, Ege University, Faculty of Medicine, Department of Hematology.

\section{Conflict of interest}

None of the authors have any interests which might influence the compilation of the current literature in this subject. We apologize to the authors whose valuable studies were not included here due to space limitations and the concentrated scope of the review.

\section{Acknowledgment}

We would like to thank Prof. Dr. Anne Frary for English editing of the article. 


\section{References}

[1] DeLellis RA, Lloyd RV, Heitz PU, Eng C. World Health Organization classification of tumors. Pathology and genetics of tumors of endocrine organs. Lyon: IARC Press; 2004.

[2] Cooper DS, Doherty GM, Haugen BR, et al. (American Thyroid Association Guidelines Taskforce) management guidelines for patients with thyroid nodules and differentiated thyroid cancer. Thyroid 2006;16:109-41.

[3] Pitoia F, Bueno F, Urciuoli C, Abelleira E, Cross G, Tuttle RM. Outcome of patients with differentiated thyroid cancer risk stratified according to the American Thyroid Association and Latin American Thyroid Society risk of recurrence classification systems. Thyroid 2013;23(11):1401-7.

[4] Pellegriti G, Frasca F, Regalbuto C, Squatrito S, Vigneri R. Worldwide increasing incidence of thyroid cancer: update on epidemiology and risk factors. J Cancer Epidemiol 2013; 2013:1-10.

[5] Kilfoy BA, Zheng T, Holford TR, et al. International patterns and trends in thyroid cancer incidence, 1973-2002. Cancer Causes Control 2009;20:525-31.

[6] Jemal A, Siegel R, Xu J, Ward E. Cancer statistics 2010. CA: Cancer J Clin 2010;60:277-300.

[7] Kent WDT, Hall SF, Isotalo PA, Houlden RL, George RL, Groome PA. Increased incidence of differentiated thyroid carcinoma and detection of subclinical disease. Can Med Assoc J 2007;177:1357-61.

[8] Jemal A, Murray T, Ward E, et al. 2005 Cancer statistics. CA Cancer J Clin 2005;55:10-30.

[9] Sherman SI. Thyroid carcinoma. Lancet 2003;361:501-11.

[10] Randolph GW, Duh QY, Heller KS, et al. The prognostic significance of nodal metastases from papillary thyroid carcinoma can be stratified based on the size and number of metastatic lymph nodes, as well as the presence of extranodal extension. Thyroid 2012;22:1144-52.

[11] Yu XM, Lloyd R, Chen H. Current treatment of papillary thyroid microcarcinoma. Adv Surg 2012;46:191-203.

[12] Meas T, Vercellino L, Faugeron I, Toubert ME. The 2009 Revised American Thyroid Association Guidelines for Thyroid Cancer: multifocality in $\mathrm{T} 1$ tumors in question, for or against a more minimalist approach? Thyroid 2013;23(8):1042-3.

[13] Lee SL. Radioactive iodine therapy. Curr Opin Endocrinol Diabetes Obes 2012;19:420-8.

[14] Nikiforov YE. Thyroid carcinoma: molecular pathways and therapeutic targets. Mod Pathol 2008;21:S37-43.

[15] Witt RL, Ferris RL, Pribitkin EA, Sherman SI, Steward DL, Nikiforov YE. Diagnosis and management of differentiated thyroid cancer using molecular biology. Laryngoscope 2013;123:1059-64.

[16] Kimura ET, Nikiforova MN, Zhu Z, Knauf JA, Nikiforov YE, Fagin JA. High prevalence of BRAF mutations in thyroid cancer: genetic evidence for constitutive activation of the RET/PTC-RASBRAF signaling pathway in papillary thyroid carcinoma. Cancer Res 2003;63:1454-7.

[17] Fagin JA. Genetics of papillary thyroid cancer initiation: implications for therapy. Trans Am Clin Climatol Assoc 2005;116:259-69.

[18] Luster M, Hänscheid H, Freudenberg LS, Verburg FA. Radioiodine therapy of metastatic lesions of differentiated thyroid cancer. J Endocrinol Invest 2012;35:21-9.

[19] Molinaro E, Pieruzzi L, Viola D. Radioiodine post-surgical remnant ablation in patients with differentiated thyroid cancer: news from the last 10 years. J Endocrinol Invest 2012;35:16-20.

[20] Boos LA, Dettmer M, Schmitt A, et al. Diagnostic and prognostic implications of the PAX8-PPAR $y$ translocation in thyroid carcinomas-a TMA-based study of 226 cases. Histopathology 2013.

[21] Goyal N, Setabutr D, Abdulghani J, Goldenberg D. Molecular and genetic markers of follicular-cell thyroid cancer: etiology and diagnostic and therapeutic opportunities. Adv Exp Med Biol 2013;779:309-26.

[22] Dai G, Levy O, Carrasco N. Cloning and characterization of the thyroid iodide transporter. Nature 1996;379:458-60.
[23] Eskandari S, Loo DDF, Dai G, Levy O, Wright EM, Carrasco N. Thyroid Na+/I- symporter: mechanism, stoichiometry, and specificity. J Biol Chem 1997;272:2723-8.

[24] Regalbuto C, Frasca F, Pellegriti G, et al. Update on thyroid cancer treatment. Future Oncol 2012;8:1331-48.

[25] Mian C, Barollo S, Pennelli G, et al. Molecular characteristics in papillary thyroid cancers (PTCs) with no 131 I uptake. Clin Endocrinol 2008;68:108-16.

[26] Nikiforov YE. Molecular diagnostics of thyroid tumors. Arch Pathol Lab Med 2011;135:569-77.

[27] Xing M, Haugen BR, Schlumberger M. Progress in molecularbased management of differentiated thyroid cancer. Lancet 2013;381:1058-69.

[28] Nikiforov YE. Molecular analysis of thyroid tumors. Mod Pathol 2011;24:S34-43.

[29] Xing M. BRAF mutation in thyroid cancer. Endocr Relat Cancer 2005; $12: 245-62$.

[30] Cohen Y, Xing M, Mambo E, et al. BRAF mutation in papillary thyroid carcinoma. J Natl Cancer Inst 2003;95:625-7.

[31] Xing M. Molecular pathogenesis and mechanisms of thyroid cancer. Nature 2013;13:184-9.

[32] Nikiforov YE, Nikiforova MN. Molecular genetics and diagnosis of thyroid cancer. Nature 2011;7:569-80.

[33] Legakis I, Syrigos K. Recent advances in molecular diagnosis of thyroid cancer. J Thyroid Res 2011; 2011:1-8.

[34] Xing M. Recent advances in molecular biology of thyroid cancer and their clinical implications. Otolaryngol Clin N Am 2008;41:1135-46.

[35] Knauf JA, Ma X, Smith EP, et al. Targeted expression of BRAFV600E in thyroid cells of transgenic mice results in papillary thyroid cancers that undergo dedifferentiation. Cancer Res 2005;15(65(10)):4238-45.

[36] Fagin JA. Challenging dogma in thyroid cancer molecular genetics - role of RET/PTC and BRAF in tumor initiation. J Clin Endocrinol Metab 2004;89:4264-6.

[37] Cahill S, Smyth P, Finn SP, et al. Effect of ret/PTC 1 rearrangement on transcription and post-transcriptional regulation in a papillary thyroid carcinoma model. Mol Cancer 2006;5:1-12.

[38] Santoro M, Dathan NA, Berlingieri MT, et al. Molecular characterization of RET/PTC3; a novel rearranged version of the RET proto-oncogene in a human thyroid papillary carcinoma. Oncogene 1994:9(2):509-16.

[39] Jhiang SM, Sagartz JE, Tong Q, et al. Targeted expression of the ret/PTC1 oncogene induces papillary thyroid carcinomas. Endocrinology 1996;137:375-8.

[40] Powell Jr DJ, Russell J, Nibu K, et al. The RET/PTC3 oncogene: metastatic solid-type papillary carcinomas in murine thyroids. Cancer Res 1998;58:5523-8.

[41] Celetti N, Cerrato A, Merolla F, Vitagliano D, Vecchio G, Grieco M. H4(D10S170), a gene frequently rearranged with RET in papillary thyroid carcinomas: functional characterization. Oncogene 2004;23:109-21.

[42] Santoro M, Melillo RM, Fusco A. RET/PTC activation in papillary thyroid carcinoma: European Journal of Endocrinology Prize Lecture. European Journal of Endocrinology 2006;155:645-53.

[43] Sapio MR, Guerra A, Marotta V, et al. High growth rate of benign thyroid nodules bearing RET/PTC rearrangements. J Clin Endocrinol Metab 2011;96(6):E916-9.

[44] Salvatore G, Giannini R, Faviana P, et al. Analysis of BRAF point mutation and RET/PTC rearrangement refines the fine-needle aspiration diagnosis of papillary thyroid carcinoma. J Clin Endocrinol Metab 2004;89(10):5175-80.

[45] Kondo T, Ezzat S, Asa SL. Pathogenetic mechanisms in thyroid follicular-cell neoplasia. Nat Rev Cancer 2006;6:292-306.

[46] Robinson MJ, Cobb MH. Mitogen-activated protein kinase pathways. Curr Opin Cell Biol 1997;9(2):180-6.

[47] Kimura ET, Nikiforova MN, Zhu Z, Knauf JA, Nikiforov YE, Fagin JA. High prevalence of BRAF mutations in thyroid cancer: genetic evidence for constitutive activation of the RET/ 
PTC-RAS-BRAF signaling pathway in papillary thyroid carcinoma. Cancer Res 2003;63(7):1454-7.

[48] Soares P, Trovisco V, Rocha AS, et al. BRAF mutations and RET/PTC rearrangements are alternative events in the etiopathogenesis of PTC. Oncogene 2003;22(29):4578-80.

[49] Frattini M, Ferrario C, Bressan P, et al. Alternative mutations of BRAF, RET and NTRK1 are associated with similar but distinct gene expression patterns in papillary thyroid cancer. Oncogene 2004;23(44):7436-40.

[50] Ciampi R, Nikiforov YE. Minireview: RET/PTC rearrangements and braf mutations in thyroid tumorigenesis. Endocrinology 2007;148(3):936-41.

[51] Davies H, Bignell GR, Cox C, et al. Mutations of the BRAF gene in human cancer. Nature 2002;417(6892):949-54.

[52] Hou P, Liu D, Xing M. Genome-wide alterations in gene methylation by the BRAF V600E mutation in papillary thyroid cancer cells. Endocr Relat Cancer 2007;18:687-97.

[53] Melillo RM, Castellone MD, Guarino V, et al. The RET/PTCRAS-BRAF linear signaling cascade mediates the motile and mitogenic phenotype of thyroid cancer cells. J Clin Invest 2005;115: 1068-81.

[54] Oler G, Camacho CP, Hojaij FC, Michaluart Jr P, Riggins GJ, Cerutti JM. Gene expression profiling of papillary thyroid carcinoma identifies transcripts correlated with BRAF mutational status and lymph node metastasis. Clin Cancer Res 2008;14:4735-42.

[55] Palona I, Namba H, Mitsutake N, et al. BRAFV600E promotes invasiveness of thyroid cancer cells through nuclear factor $\mathrm{\kappa B}$ activation. Endocrinology 2006;147:5699-707.

[56] Jo YS, Li S, Song JH, et al. Influence of the BRAF V600E mutation on expression of vascular endothelial growth factor in papillary thyroid cancer. J Clin Endocrinol Metab 2006;91:3667-70.

[57] Mesa Jr C, Mirza M, Mitsutake N, et al. Conditional activation of RET/PTC3 and BRAFV600E in thyroid cells is associated with gene expression profiles that predict a preferential role of BRAF in extracellular matrix remodeling. Cancer Res 2006;66:6521-9.

[58] Mesa Jr C, Mirza M, Mitsutake N, et al. Molecular classification of papillary thyroid carcinoma: distinct BRAF RAS, and RET/PTC mutation-specific gene expression profiles discovered by DNA microarray analysis. Oncogene 2005;24:6646-56.

[59] Kumagai A, Namba H, Mitsutake N, et al. Childhood thyroid carcinoma with BRAFT1799A mutation shows unique pathological features of poor differentiation. Oncol Rep 2006;16:123-6.

[60] Watanabe R, Hayashi Y, Sassa M, et al. Possible involvement of BRAFV600E in altered gene expression in papillary thyroid cancer. Endocr J 2009;56:407-14.

[61] Pasquali D, Santoro A, Bufo P, et al. Upregulation of endocrine glandderived vascular endothelial growth factor in papillary thyroid cancers displaying infiltrative patterns, lymph node metastases, and BRAF mutation. Thyroid 2011;21:391-9.

[62] Franzoni A, Dima M, D'Agostino M, et al. Prohibitin is overexpressed in papillary thyroid carcinomas bearing the BRAF(V600E) mutation. Thyroid 2009;19:247-55.

[63] Zerilli M, Zito G, Martorana A, et al. BRAF(V600E) mutation influences hypoxia-inducible factor $1 \alpha$ expression levels in papillary thyroid cancer. Mod Pathol 2010;23:1052-60.

[64] Nucera C, Porrello A, Antonello ZA, et al. B Raf(V600E) and thrombospondin 1 promote thyroid cancer progression. Proc Natl Acad Sci USA 2010;107:54-1064.

[65] Nowicki TS, Kummer NT, Iacob C, et al. Inhibition of uPAR and UPA reduces invasion in papillary thyroid carcinoma cells. Laryngoscope 2010;120:1383-90.

[66] Nowicki TS, Zhao H, Darzynkiewicz Z, et al. Downregulation of UPAR inhibits migration, invasion, proliferation, FAK/PI3K/Akt signaling and induces senescence in papillary thyroid carcinoma cells. Cell Cycle 2011;10:100-7.

[67] Riesco-Eizaguirre G, Rodríguez I, De la Vieja A, et al. The BRAFV600E oncogene induces transforming growth factor $\beta$ secretion leading to sodium iodide symporter repression and increased malignancy in thyroid cancer. Cancer Res 2009;69:8317-25.

[68] Knauf JA, Sartor MA, Medvedovic M, et al. Progression of BRAFinduced thyroid cancer is associated with epithelial-mesenchymal transition requiring concomitant MAP kinase and TGF $\beta$ signaling. Oncogene 2011;30:3153-62.

[69] Mian C, Barollo S, Pennelli G, et al. Molecular characteristics in papillary thyroid cancers (PTCs) with no ${ }^{131}$ I uptake. Clin Endocrinol 2008;68(1):108-16.

[70] Vivanco I, Sawyers CL. The phosphatidylinositol 3-kinase-AKT pathway in human cancer. Nat Rev Cancer 2002;2:489-501.

[71] Xing M. Genetic alterations in the phosphatidylinositol 3 kinase/Akt pathway in thyroid cancer. Thyroid 2010;20:697-706.

[72] Saji M, Ringel MD. The PI3K Akt-mTOR pathway in initiation and progression of thyroid tumors. Mol Cell Endocrinol 2010;321: $20-8$.

[73] Liaw D, Marsh DJ, Li J, et al. Germline mutations of the PTEN gene in Cowden disease, an inherited breast and thyroid cancer syndrome. Nat Genet 1997;16:64-7.

[74] Ringel MD, Hayre N, Saito J, et al. Overexpression and overactivation of Akt in thyroid carcinoma. Cancer Res 2001;61(16):6105-11.

[75] Vasko V, Saji M, Hardy E, et al. Akt activation and localisation correlate with tumor invasion and oncogene expression in thyroid cancer. J Med Genet 2004;41(3):161-70.

[76] Ringel MD, Hayre N, Saito J, et al. Overexpression and overactivation of Akt in thyroid carcinoma. Cancer Res 2001;61:6105-11.

[77] García-Rostán G, Costa AM, Pereira-Castro I, et al. Mutation of the PIK3CA gene in anaplastic thyroid cancer. Cancer Res 2005;65(22):10199-207.

[78] Wu G, Mambo E, Guo Z, et al. Uncommon mutation, but common amplifications, of the PIK3CA gene in thyroid tumors. J Clin Endocrinol Metab 2005;90(8):4688-93.

[79] Hou P, Liu D, Shan Y, et al. Genetic alterations and their relationship in the phosphatidylinositol 3-kinase/Akt pathway in thyroid cancer. Clin Cancer Res 2007;13(4):1161-70.

[80] Fresno Vara JA, Casado E, de Castro J, Cejas P, Belda-Iniesta C, González-Barón M. P13K/Akt signaling pathway and cancer. Cancer Treat Rev 2004;2(30):193-204.

[81] Suzuki H, Willingham MC, Cheng SY. Mice with a mutation in the thyroid hormone receptor $\beta$ gene spontaneously develop thyroid carcinoma: a mouse model of thyroid carcinogenesis. Thyroid 2002;12:963-9.

[82] Furuya F, Hanover JA, Cheng SY. Activation of phosphatidylinositol 3 kinase signaling by a mutant thyroid hormone $\beta$ receptor. Proc Natl Acad Sci USA 2006;103:1780-5.

[83] Vasko V, Saji M, Hardy E, et al. Akt activation and localisation correlate with tumor invasion and oncogene expression in thyroid cancer. J Med Genet 2004;41:161-70.

[84] Ricarte-Filho JC, Ryder M, Chitale DA, et al. Mutational profile of advanced primary and metastatic radioactive iodine-refractory thyroid cancers reveals distinct pathogenetic roles for BRAF, PIK3CA, and AKT1. Cancer Res 2009;69:4885-93.

[85] Saji M, Narahara K, McCarty SK, et al. Akt1 deficiency delays tumor progression, vascular invasion, and distant metastasis in a murine model of thyroid cancer. Oncogene 2011;30:4307-15.

[86] Fagin JA, Matsuo K, Karmakar A, Chen DL, Tang SH, Koeffler HP. High prevalence of mutations of the p53 gene in poorly differentiated human thyroid carcinomas. J Clin Invest 1993;91(1): $179-84$.

[87] Suarez HG, du Villard JA, Severino M, et al. Presence of mutations in all three ras genes in human thyroid tumors. Oncogene 1990;5:565-70.

[88] Ezzat S, Zheng L, Kolenda J, Safarian A, Freeman JL, Asa SL. Prevalence of activating ras mutations in morphologically characterized thyroid nodules. Thyroid 1996;6:409-16.

[89] Meinkoth JL. Biology of Ras in thyroid cells. Treat Res 2004;122:131-48. 
[90] Esapa CT, Johnson SJ, Kendall-Taylor P, Lennard TW, Harris PE. Prevalence of Ras mutations in thyroid neoplasia. Clin Endocrinol (Oxf) 1999;50:529-35.

[91] Motoi N, Sakamoto A, Yamochi T, Horiuchi H, Motoi T, Machinami $\mathrm{R}$. Role of ras mutation in the progression of thyroid carcinoma of follicular epithelial origin. Pathol Res Pract 2000;196:1-7.

[92] Manenti G, Pilotti S, Re FC, Della Porta G, Pierotti MA. Selective activation of ras oncogenes in follicular and undifferentiated thyroid carcinomas. Eur J Cancer 1994;30A:987-93.

[93] Namba H, Rubin SA, Fagin JA. Point mutations of ras oncogenes are an early event in thyroid tumorigenesis. Mol Endocrinol 1990;4:1474-9.

[94] Adeniran AJ, Zhu Z, Gandhi M, et al. Correlation between genetic alterations and microscopic features, clinical manifestations, and prognostic characteristics of thyroid papillary carcinomas. Am J Surg Pathol 2006;30:216-22.

[95] Zhu Z, Gandhi M, Nikiforova MN, Fischer AH, Nikiforov YE. Molecular profile and clinical-pathologic features of the follicular variant of papillary thyroid carcinoma. An unusually high prevalence of ras mutations. Am J Clin Pathol 2003;120:71-7.

[96] Lemoine NR, Mayall ES, Wyllie FS, et al. High frequency of ras oncogene activation in all stages of human thyroid tumorigenesis. Oncogene 1989;4:159-64.

[97] Basolo F, Pisaturo F, Pollina LE, et al. N-ras mutation in poorly differentiated thyroid carcinomas: correlation with bone metastases and inverse correlation to thyroglobulin expression. Thyroid 2000;10(1):19-23.

[98] Esapa CT, Johnson SJ, Kendall-Taylor P, Lennard TW, Harris PE. Prevalence of Ras mutations in thyroid neoplasia. Clin Endocrinol 1999:50(4):529-35.

[99] Motoi N, Sakamoto A, Yamochi T, Horiouchi H, Motoi T, Machinami $\mathrm{R}$. Role of ras mutation in the progression of thyroid carcinoma of follicular epithelial origin. Pathol Res Pract 2000;196(1):1-7.

[100] Rochefort P, Caillou B, Michiels FM, et al. Thyroid pathologies in transgenic mice expressing a human activated Ras genedriven by a thyroglobulin promoter. Oncogene 1996;12(1):111-8.

[101] Kroll TG, Sarraf P, Pecciarini L, et al. PAX8-PPARgamma1 fusion oncogene in human thyroid carcinoma. Science 2000;289:1357-60.

[102] Wang Y, Hou P, Yu H, et al. High prevalence and mutual exclusivity of genetic alterations in the phosohatidiylinositol-3-kinase/Akt pathway in thyroid tumors. J Clin Endocrinol Metab 2007;92(6):2387-90.

[103] Kroll TG, Sarraf P, Pecciarini L, et al. PAX8-PPAR gamma1 fusion oncogene in human thyroid carcinoma. Science 2000;289:1357-60.

[104] Gregory Powell J, Wang X, Allard BL, et al. The PAX8/PPARgamma fusion oncoprotein transforms immortalized human thyrocytes through a mechanism probably involving wild-type PPARgamma inhibition. Oncogene 2004;23:3634-41.

[105] Tallini G. Molecular pathobiology of thyroid neoplasms. Endocr Pathol 2002;13(4):271-88.

[106] Kroll TG, Sarraf P, Pecciarini L, et al. PAX8-PPAR 1 fusion in oncogene human thyroid carcinoma. Science 2000;289(5483):1357-60.

[107] Giordano TJ, Au AY, Kuick R, et al. Delineation, functional validation, and bioinformatic evaluation of gene expression in thyroid follicular carcinomas with the PAX8-PPARG translocation. Clin Cancer Res 1983;12(7 Pt 1):93.

[108] Reddi HV, McIver B, Grebe SK, Eberhardt NL. The paired box8/peroxisome proliferator-activated receptor-gamma oncogene in thyroid tumorigenesis. Endocrinology 2007;148(3):932-5.

[109] French CA, Alexander EK, Cibas ES, et al. Genetic and biological subgroups of low-stage follicular thyroid cancer. Am J Pathol 2003;162:1053-60.

[110] Nikiforova MN, Lynch RA, Biddinger PW, et al. RAS point mutations and PAX8-PPAR gamma rearrangement in thyroid tumors: evidence for distinct molecular pathways in thyroid follicular carcinoma. J Clin Endocrinol Metab 2003;88:2318-26.

[111] Dwight T, Thoppe SR, Foukakis T, et al. Involvement of the PAX8/peroxisome proliferator-activated receptor gamma rearrangement in follicular thyroid tumors. J Clin Endocrinol Metab 2003:88:4440-5.

[112] Nikiforova MN, Biddinger PW, Caudill CM, Kroll TG, Nikiforov YE. PAX8-PPARgamma rearrangement in thyroid tumors: RT-PCR and immunohistochemical analyses. Am J Surg Pathol 2002;26: 1016-23.

[113] Marques AR, Espadinha C, Catarino AL, et al. Expression of PAX8-PPAR gamma 1 rearrangements in both follicular thyroid carcinomas and adenomas. J Clin Endocrinol Metab 2002;87: $3947-52$

[114] Lui WO, Zeng L, Rehrmann V, et al. CREB3L2-PPARgamma fusion mutation identifies a thyroid signaling pathway regulated by intramembrane proteolysis. Cancer Res 2008;68:7156-64.

[115] Farid NR, Shi Y, Zou M. Molecular basis of thyroid cancer. Endocr Rev 1994;15(2):202-32.

[116] Segev DL, Umbricht C, Zeiger MA. Molecular pathogenesis of thyroid cancer. Surg Oncol 2003;12(2):69-90.

[117] Donghi R, Longoni A, Pilotti S, Michieli P, Della Porta G, Pierotti MA. Gene p53 mutations are restricted to poorly differentiated and undifferentiated carcinomas of the thyroid gland. J Clin Invest 1993;91(4):1753-60.

[118] Dobashi Y, Sugimura H, Sakamoto A, et al. Stepwise participation of p53 gene mutation during dedifferentiation of human thyroid carcinomas. Diagn Mol Pathol 1994;3(1):9-14.

[119] Ho YS, Tseng SC, Chin TY, Hsieh LL, Lin JD. p53 gene mutation in thyroid carcinoma. Cancer Lett 1996;103(1):57-63.

[120] Takeuchi Y, Daa T, Kashima K, Yokoyama S, Nakayama I, Noguchi S. Mutations of p53 in thyroid carcinoma with an insular component. Thyroid 1999;9(4):377-81.

[121] Moretti F, Farsetti A, Soddu S, et al. p53 re-expression inhibits proliferation and restores differentiation of human thyroid anaplastic carcinoma cells. Oncogene 1997;14(6):729-40.

[122] Fagin JA, Tang SH, Zeki K, Di Lauro R, Fusco A, Gonsky R. Reexpression of thyroid peroxidase in a derivative of an undifferentiated thyroid carcinoma cell line by introduction of wild-type p53. Cancer Res 1996;56(4):765-71.

[123] Smallridge RC, Marlow LA, Copland JA. Anaplastic thyroid cancer: molecular pathogenesis and emerging therapies. Endocr Relat Cancer 2009;16:17-44.

[124] Nikiforov YE. Genetic alterations involved in the transition from well-differentiated to poorly differentiated and anaplastic thyroid carcinomas. Endocr Pathol 2004;15:319-27.

[125] Xing M. Genetic alterations in the phosphatidylinositol-3 kinase/Akt pathway in thyroid cancer. Thyroid 2010;20:697-706.

[126] La Perle KMD, Jhiang SM, Capen CC. Loss of p53 promotes anaplasia and local invasion in ret/PTC1-induced thyroid carcinomas. Am J Pathol 2000;157(2):671-7.

[127] Powell Jr DJ, Russell JP, Li G, et al. Altered gene expression in immunogenic poorly differentiated thyroid carcinomas fromRET/PTC3p53-/- mice. Oncogene 2001;20(25):3235-46.

[128] Polakis P. The many ways of Wnt in cancer. Curr Opin Genet Dev 2007; 17:45-51.

[129] Kraus C, Liehr T, Hülsken J, et al. Localization of the human betacatenin gene (CTNNB1) to 3p21: a region implicated in tumor development. Genomics 1994;23(1):272-4.

[130] van Hengel J, Nollet F, Berx G, van Roy N, Speleman F, van Roy F. Assignment of the human beta-catenin gene (CTNNB1) to 3p22p21.3 by fluorescence in situ hybridization. Cytogenet Cell Genet 1995;70(1-2):68-70.

[131] Garcia-Rostan G, Camp RL, Herrero A, Carcangiu ML, Rimm DL, Tallini G. Beta-catenin dysregulation in thyroid neoplasms: down-regulation, aberrant nuclear expression, and CTNNB1 exon 3 mutations are markers for aggressive tumor phenotypes and poor prognosis. Am J Pathol 2001;158(3):987-96.

[132] Miyake N, Maeta H, Horie S, et al. Absence of mutations in the beta-catenin and adenomatous polyposis coli genes in papillary and follicular thyroid carcinomas. Pathol Int 2001;51(9):680-5. 
[133] Karin M. NF-кB as a critical link between inflammation and cancer. Cold Spring Harb Perspect Biol 2009;1(5):000141.

[134] Pacifico F, Mauro C, Barone C, et al. Oncogenic and anti-apoptotic activity of NF- $\mathrm{KB}$ in human thyroid carcinomas. J Bio Chem 2004;279:5461-9.

[135] Visconti R, Cerutti J, Battista S, et al. Expression of the neoplastic phenotype by human thyroid carcinoma cell lines requires NFKB p65 protein expression. Oncogene 1997;15:1987-94.

[136] Mitsiades CS, McMillin D, Kotoula V, et al. Antitumor effects of the proteasome inhibitor bortezomib in medullary and anaplastic thyroid carcinoma cells in vitro. J Clin Endocrinol Metab 2006;91:4013-21.

[137] Pacifico F, Leonardi A. Role of NF-кB in thyroid cancer. Mol Cell Endocrinol 2010;321:29-35.

[138] Li X, Abdel-Mageed AB, Mondal D, Kandil E. The nuclear factor К-B signaling pathway as a therapeutic target against thyroid cancers. Thyroid 2012. Epub ahead of print.

[139] Zhou YL, Liu C, Dai X, Zhang XH, Wang OC. Overexpression of miR-221 is associated with aggressive clinicopathologic characteristics and the BRAF mutation in papillary thyroid carcinomas. Med Oncol 2012;29:3360-6.

[140] Greco A, Borrello MG, Miranda C, Degl'Innocenti D, Pierotti MA. Molecular pathology of differentiated thyroid cancer. Q J Nucl Med Mol Imaging 2009;53(5):440-53.

[141] Lu J, Getz G, Miska EA, et al. MicroRNA expression profiles classify human cancers. Nature 2005;435:834-8.

[142] Volinia S, Calin GA, Liu CG, et al. A microRNA expression signature of human solid tumors defines cancer gene targets. Proc Natl Acad Sci 2006;103(7):2257-61.

[143] Pallante P, Visone R, Ferracin M, et al. MicroRNA deregulation in human thyroid papillary carcinomas. Endocr Relat Cancer 2006;13:497-508.

[144] Nikiforova MN, Tseng GC, Steward D, Diorio D, Nikiforov YE. MicroRNA expression profiling of thyroid tumors: biological significance and diagnostic utility. J Clin Endocrinol Metab 2008;93(5):1600-8.

[145] Schwertheim S, Sheu SY, Worm K, Grabellus F, Schmid KW. Analysis of deregulated miRNAs is helpful to distinguish poorly differentiated thyroid carcinoma from papillary thyroid carcinoma. Horm Metab Res 2009;41:475-81.

[146] He H, Jazdzewski K, Li W, et al. The role of microRNA genes in papillary thyroid carcinoma. Proc Natl Acad Sci 2005;102(52): 19075-80.

[147] Chou CK, Chen RF, Chou FF, et al. miR-146b is highly expressed in adult papillary thyroid carcinomas with high risk features including extrathyroidal invasion and the BRAF(V600E) mutation. Thyroid 2010;20(5):489-94.

[148] Wang S, Wuu J, Savas L, Patwardhan N, Khan A. The role of cell cycle regulatory proteins, cyclin D1, cyclin E, and p27 in thyroid carcinogenesis. Hum Pathol 1998;29(11):1304-9.

[149] Chou CK, Yang KD, Chou FF, et al. Prognostic implications of miR146b expression and its functional role in papillary thyroid carcinoma. J Clin Endocrinol Metab 2013;98(2):E196-205.

[150] Geraldo MV, Yamashita AS, Kimura ET. MicroRNA miR-146b-5p regulates signal transduction of TGF- $\beta$ by repressing SMAD4 in thyroid cancer. Oncogene 2012;31:1910-22.

[151] Wang Z, Zhang H, He L, et al. Association between the expression of four upregulated miRNAs and extrathyroidal invasion in papillary thyroid carcinoma. Onco Targets Ther 2013;6:281-7.

[152] Wang Z, Zhang H, Zhang P, Li J, Shan Z, Teng W. Upregulation of miR-2861 and miR-451 expression in papillary thyroid carcinoma with lymph node metastasis. Med Oncol 2013;30:577.

[153] Yu S, Liu Y, Wang J, et al. Circulating MicroRNA profiles as potential biomarkers for diagnosis of papillary thyroid carcinoma. J Clin Endocrinol Metab 2012;97(6):2084-92.

[154] Pallante P, Visone R, Croce CM, Fusco A. Deregulation of microRNA expression in follicular cell-derived human thyroid carcinomas. Endocr Relat Cancer 2010;17:F91-104.
[155] Castellone MD, Guarino V, De Falco V, et al. Functional expression of the CXCR4 chemokine receptor is induced by RET/PTC oncogenes and is a common event in human papillary thyroid carcinomas. Oncogene 2004;23:5958-67.

[156] Weber F, Teresi RE, Broelsch CE, Frilling A, Eng C. A limited set of human microRNA is deregulated in follicular thyroid carcinoma. J Clin Endocrinol Metab 2006;91:3584-91.

[157] Argraves WS, Greene LM, Cooley MA, Gallagher WM. Fibulins: physiological and disease perspectives. EMBO Rep 2003;4:1127-31.

[158] Schulte KM, Jonas C, Krebs R, Roher HD. Activin A and activin receptors in thyroid cancer. Thyroid 2001;11:3-14.

[159] Boucheix C, Duc GH, Jasmin C, Rubinstein E. Tetraspanins and malignancy. Expert Rev Mol Med 2001; 2001:1-17.

[160] Choi KS, Bae MK, Jeong JW, Moon HE, Kim KW. Hypoxiainduced angiogenesis during carcinogenesis. J Biochem Mol Biol 2003;36:120-7.

[161] Burrows N, Resch J, Cowen RL, et al. Expression of hypoxiainducible factor $1 \alpha$ in thyroid carcinomas. Endocr Relat Cancer 2010;17:61-72.

[162] Scarpino S, Cancellario d'Alena F, Di Napoli A, Pasquini A, Marzullo A, Ruco LP. Increased expression of Met protein is associated with up-regulation of hypoxia inducible factor-1 (HIF-1) in tumor cells in papillary carcinoma of the thyroid. J Pathol 2004;202:352-8.

[163] Mo JH, Choi IJ, Jeong WJ, Jeon EH, Ahn SH. HIF-1 $\alpha$ and HSP90: target molecules selected from a tumorigenic papillary thyroid carcinoma cell line. Cancer Sci 2012;103(3):464-71.

[164] Burrows N, Babur M, Resch J, et al. GDC-0941 inhibits metastatic characteristics of thyroid carcinomas by targeting both the phosphoinositide-3 kinase (PI3K) and hypoxia inducible factor- $1 \alpha$ (HIF-1 $\alpha$ ) pathways. J Clin Endocrinol Metab 2011;96: e1934-43.

[165] Zerilli M, Zito G, Martorana A, et al. BRAF(V600E) mutation influences hypoxia-inducible factor- $1 \alpha$ expression levels in papillary thyroid cancer. Mod Pathol 2010;23(8):1052-60.

[166] Burrows N, Babur M, Resch J, et al. GDC-0941 inhibits metastatic characteristics of thyroid carcinomas by targeting both the phosphoinositide-3 kinase (PI3K) and hypoxia-inducible factor$1 \alpha$ (HIF-1 $\alpha$ ) pathways. Clin Endocrinol Metab 2011;96(12): E1934-43.

[167] Koperek O, Bergner O, Pichlhöfer B, et al. Expression of hypoxiaassociated proteins in sporadic medullary thyroid cancer is associated with desmoplastic stroma reaction and lymph node metastasis and may indicate somatic mutations in the VHL gene. J Pathol 2011;225(1):63-72.

[168] Xing M. Gene methylation in thyroid tumorigenesis. Endocrinology 2007;148:948-53.

[169] Hu S, Liu D, Tufano RP, et al. Association of aberrant methylation of tumor suppressor genes with tumor aggressiveness and BRAF mutation in papillary thyroid cancer. Int J Cancer 2006;119: 2322-9.

[170] Hou P, Liu D, Xing M. Genome-wide alterations in gene methylation by the BRAF V600E mutation in papillary thyroid cancer cells. Endocr Relat Cancer 2011;18:687-97.

[171] Hou P, Ji M, Xing M. Association of PTEN gene methylation with genetic alterations in the phosphatidylinositol 3-kinase/AKT signaling pathway in thyroid tumors. Cancer 2008;113:2440-7.

[172] Alvarez-Nuñez F, Bussaglia E, Mauricio D, et al. PTEN promoter methylation in sporadic thyroid carcinomas. Thyroid 2006;16:17-23.

[173] Frisk T, Foukakis T, Dwight T, et al. Silencing of the PTEN tumorsuppressor gene in anaplastic thyroid cancer. Genes Chromosomes Cancer 2002;35:74-80.

[174] Bruni P, Boccia A, Baldassarre G, et al. PTEN expression is reduced in a subset of sporadic thyroid carcinomas: evidence that PTENgrowth suppressing activity in thyroid cancer cells mediated by p27kip1. Oncogene 2000;19:3146-55.

[175] Cibas ES, Ali SZ. The Bethesda system for reporting thyroid cytopathology. Am J Clin Pathol 2009;132:658-65. 
[176] Fassina AS, Montesco MC, Ninfo V, Denti P, Masarotto G. Histological evaluation of thyroid carcinomas: reproducibility of the "WHO" classification. Tumori 1993;79:314-20.

[177] Franc B, de la Salmoniere P, Lange F, et al. Interobserver and intraobserver reproducibility in the histopathology of follicular thyroid carcinoma. Hum Pathol 2003;34:1092-100.

[178] Eszlinger M, Krohn K, Hauptmann S, Dralle H, Giordano TJ, Paschke R. Perspectives for improved and more accurate classification of thyroid epithelial tumors. J Clin Endocrinol Metab 2008;93: 3286-94.

[179] Faggiano A, Caillou B, Lacroix L, et al. Functional characterization of human thyroid tissue with immunohistochemistry. Thyroid 2007;17:203-11.

[180] Fusco A, Santoro M. 20 years of RET/PTC in thyroid cancer: clinic-pathological correlations. Arq Bras Endocrinol Metab 2007;51:731-5.

[181] Marotta V, Guerra A, Sapio MR, Vitale M. RET/PTC rearrangement in benign and malignant thyroid disease: a clinical standpoint. Eur J Endocrinol 2011;165:499-507.

[182] Clark DP. Molecular diagnostics on thyroid fine-needle aspirations. Cancer Cytopathol 2010;25:14-6.

[183] Fusco A, Grieco M, Santoro M, et al. A new oncogene in human thyroid papillary carcinomas and their lymph-nodal metastases. Nature 1987;328:170-3.

[184] Grieco M, Santoro M, Berlingieri MT, et al. PTC is a novel rearranged form of the RET proto-oncogene and is frequently detected in vivo in human thyroid papillary carcinomas. Cell 1990;60:557-63.

[185] Santoro M, Melillo RM, Fusco A. RET/PTC activation in papillary thyroid carcinoma. Eur J Endocrinol 2006;155:645-53.

[186] Chiappetta G, Toti P, Cetta F, et al. The RET/PTC oncogene is frequently activated in oncocytic thyroid tumors (Hürthle cell adenomas and carcinomas), but not in oncocytic hyperplastic lesions. J Clin Endocrinol Metab 2002;87:364-9.

[187] Rhoden KJ, Unger K, Salvatore G, et al. RET/papillary thyroid cancer rearrangement in nonneoplastic thyrocytes: follicular cells of Hashimoto's thyroiditis share low-level recombination events with a subset of papillary carcinoma. J Clin Endocrinol Metab 2006:91:2414-23.

[188] Guerra A, Sapio MR, Marotta V, et al. Prevalence of RET/PTC rearrangement in benign and malignant thyroid nodules and its clinical application. Endocr J 2011;58:31-8.

[189] Marotta V, Guerra A, Sapio MR, et al. Growing thyroid nodules with benign histology and RET rearrangement. Endocr J 2010;57:1081-7.

[190] Sapio MR, Guerra A, Marotta V, et al. High growth rate of benign thyroid nodules bearing RET/PTC rearrangements. J Clin Endocrinol Metab 2011;96:E916-9.

[191] Tallini G, Santoro M, Helie M, et al. RET/PTC oncogene activation defines a subset of papillary thyroid carcinomas lacking evidence of progression to poorly differentiated or undifferentiated tumor phenotypes. Clin Cancer Res 1998;4:287-94.

[192] Thomas GA, Bunnell H, Cook HA, et al. High prevalence of RET/PTC rearrangements in Ukrainian and Belarussian post-Chernobyl thyroid papillary carcinomas: a strong correlation between RET/PTC3 and the solid-follicular variant. J Clin Endocrinol Metab 1999;84: 4232-8.

[193] Rabes HM, Demidchik EP, Sidorow JD, et al. Pattern of radiationinduced RET and NTRK1 rearrangements in 191 post-Chernobyl papillary thyroid carcinomas: biological, phenotypic, and clinical implications. Clin Cancer Res 2000;6:1093-103.

[194] Elisei R, Romei C, Vorontsova T, et al. RET/PTC rearrangements in thyroid nodules: studies in irradiated and not irradiated malignant and benign thyroid lesions in children and adults,. J Clin Endocrinol Metab 2001;86(7):3211-6.

[195] Fusco A, Chiappetta G, Hui P, et al. Assessment of RET/PTC oncogene activation and clonality in thyroid nodules with incomplete morphological evidence of papillary carcinoma: a search for the early precursors of papillary cancer. Am J Pathol 2002;160(6):2157-67.
[196] Nikiforov YE, Steward DL, Robinson-Smith TM, et al. Molecular testing for mutations in improving the fine-needle aspiration diagnosis of thyroid nodules. J Clin Endocrinol Metab 2009;94(6):2092-8.

[197] Cantara S, Capezzone M, Marchisotta S, et al. Impact of protooncogene mutation detection in cytological specimens from thyroid nodules improves the diagnostic accuracy of cytology. J Clin Endocrinol Metab 2010;95:1365-9.

[198] Pizzolanti G, Russo L, Richiusa P, et al. Fine-needle aspiration molecular analysis for the diagnosis of papillary thyroid carcinoma through BRAFV600E mutation and RET/PTC rearrangement. Thyroid 2007;17:1109-15.

[199] Tufano RP, Teixeira GV, Bishop J, Carson KA, Xing M. BRAF mutation in papillary thyroid cancer and its value in tailoring initial treatment: a systematic review and meta-analysis. Medicine 2012;91:274-86.

[200] Xing M. Prognostic utility of BRAF mutation in papillary thyroid cancer. Mol Cell Endocrinol 2010;321:86-93.

[201] Xing M, Westra WH, Tufano RP, et al. BRAF mutation predicts a poorer clinical prognosis for papillary thyroid cancer. J Clin Endocrinol Metab 2005;90:6373-9.

[202] Romei C, Ciampi R, Faviana P, et al. BRAFV600E mutation, but not RET/PTC rearrangements, is correlated with a lower expression of both thyroperoxidase and sodium iodide symporter genes in papillary thyroid cancer. Endocr Relat Cancer 2008;15:511-20.

[203] Jin L, Sebo TJ, Nakamura N, et al. BRAF mutation analysis in fine needle aspiration (FNAB) cytology of the thyroid. Diagn Mol Pathol 2006;15:136-43.

[204] Cohen Y, Rosenbaum E, Clark DP, et al. Mutational analysis of BRAF in fine needle aspiration biopsies of the thyroid: a potential application for the preoperative assessment of thyroid nodules. Clin Cancer Res 2004:10:2761-5.

[205] Sapio MR, Posca D, Raggioli A, et al. Detection of RET/PTC, TRK and BRAF mutations in preoperative diagnosis of thyroid nodules with indeterminate cytological findings. Clin Endocrinol (Oxf) 2007;66(5):678-83.

[206] Pizzolanti G, Russo L, Richiusa P, et al. Fine-needle aspiration molecular analysis for the diagnosis of papillary thyroid carcinoma through BRAF(V600E) mutation and RET/PTC rearrangement. Thyroid 2007;17:1109-15.

[207] Nikiforova MN, Nikiforov YE. Molecular diagnostics and predictors in thyroid cancer. Thyroid 2009;19:61.

[208] Kim SK, Hwang TS, Yoo YB, et al. Surgical results of thyroid nodules according to a management guideline based on the BRAF(V600E) mutation status. J Clin Endocrinol Metab 2011;96: 658-64.

[209] Kim SW, Lee JI, Kim JW, et al. BRAFV600E mutation analysis in fine-needle aspiration cytology specimens for evaluation of thyroid nodule: a large series in a BRAFV600E-prevalent population. J Clin Endocrinol Metab 2010;95:3693-700.

[210] Rowe LM, Bentz BM, Bentz JM. Utility of BRAF V600E mutation detection in cytologically indeterminate thyroid nodules. Cytojournal 2006;3:10.

[211] Ohori NP, Nikiforov MN. Contribution of molecular testing to thyroid fine needle aspiration cytology of follicular lesion of undeterminated significance/atypia of underdetermined significance. Cancer (Cytopathology) 2010;118:17-23.

[212] Moses W, Weng J, Sansano I, et al. Molecular testing for somatic mutations improves the accuracy of thyroid fine-needle aspiration biopsy. World J Surg 2010;34:2589-94.

[213] Cooper DS, Doherty GM, Haugen BR, et al. Revised American Thyroid Association management guidelines for patients with thyroid nodules and differentiated thyroid cancer. Thyroid 2009;19:1167-214.

[214] Baloch ZW, LiVolsi VA, Asa SL, et al. Diagnostic terminology and morphologic criteria for cytologic diagnosis of thyroid lesions: a synopsis of the National Cancer Institute Thyroid Fine-Needle Aspiration State of the Science Conference. Diagn Cytopathol 2008;36:425-37. 
[215] Lubitz CC, Fahey 3rd TJ. The differentiation of benign and malignant thyroid nodules. Adv Surg 2005;39:355-77.

[216] Prasad NB, Somervell H, Tufano RP, et al. Identification of genes differentially expressed in benign versus malignant thyroid tumors. Clin Cancer Res 2008;14:3327-37.

[217] Belge G, Meyer A, Klemke M, et al. Upregulation of HMGA2 in thyroid carcinomas: a novel molecular marker to distinguish between benign and malignant follicular neoplasias. Genes Chromosomes Cancer 2008;47:656-63.

[218] Chiappetta G, Ferraro A, Vuttariello E, et al. HMGA2 mRNA expression correlates with the malignant phenotype in human thyroid neoplasias. Eur J Cancer 2008;44:1015-21.

[219] Lappinga PJ, Kip NS, Jin L, et al. HMGA2 gene expression analysis performed on cytologic smears to distinguish benign from malignant thyroid nodules. Cancer Cytopathol 2010;118:287-97.

[220] Griffith OL, Melck A, Jones SJM, Wiseman SM. Meta-analysis and meta-review of thyroid cancer gene expression profiling studies identifies important diagnostic biomarkers. J Clin Oncol 2006;24:5043-51.

[221] Chudova D, Wilde JI, Wang ET, et al. Molecular classification of thyroid nodules using high-dimensionality genomic data. J Clin Endocrin Metab 2010;95:5296-304.

[222] Mathur A, Weng J, Moses W, et al. A prospective study evaluating the accuracy of using combined clinical factors and candidate diagnostic markers to refine the accuracy of thyroid fine needle aspiration biopsy. Surgery 2010;148:1170-6.

[223] Nikiforova MN, Chiosea SI, Nikiforov YE. MicroRNA expression profiles in thyroid tumors. Endocr Pathol 2009;20:85-91.

[224] Wan PT, Garnett MJ, Roe SM, et al. Mechanism of activation of the RAF-ERK signaling pathway by oncogenic mutations of B-RAF. Cell 2004;116(6):855-67.

[225] Wilhelm SM, Carter C, Tang L, et al. BAY 43-9006 exhibits broad spectrum oral antitumor activity and targets the RAF/MEK/ERK pathway and receptor tyrosine kinases involved in tumor progression and angiogenesis. Cancer Res 2004;64(19):7099-109.

[226] Salvatore G, De Falco V, Salerno P, et al. BRAF is a therapeutic target in aggressive thyroid carcinoma. Clin Cancer Res 2006;12(5): $1623-9$.

[227] Carlomagno F, Anaganti S, Guida T, et al. BAY 43-9006 inhibition of oncogenic RET mutants. J Natl Cancer Inst 2006;98:326-34.

[228] Baudin E, Schlumberger M. New therapeutic approaches for metastatic thyroid carcinoma. Lancet Oncol 2007;8:148-56.

[229] Espinosa AV, Porchia L, Ringel MD. Targeting BRAF in thyroid cancer. Br J Cancer 2007;96:16-20.

[230] Ouyang B, Knauf JA, Smith EP, et al. Inhibitors of Raf kinase activity block growth of thyroid cancer cells with RET/PTC or BRAF mutations in vitro and in vivo. Clin Cancer Res 2006;12:1785-93.

[231] Solit DB, Garraway LA, Pratilas CA, et al. BRAF mutation predicts sensitivity to MEK inhibition. Nature 2006;439:358-62.

[232] Herbst RS, Heymach JV, O’Reilly MS, Onn A, Ryan AJ. Vandetanib (ZD6474): an orally available receptor tyrosine kinase inhibitor that selectively targets pathways critical for tumor growth and angiogenesis. Expert Opin Invest Drugs 2007;16:239-49.

[233] Carlomagno F, Vitagliano D, Guida T, et al. ZD6474, an orally available inhibitor of KDR tyrosine kinase activity, efficiently blocks oncogenic RET kinases. Cancer Res 2002;62(24):7284-90.

[234] Santoro M, Carlomagno F. Drug insight: small-molecule inhibitors of protein kinases in the treatment of thyroid cancer. Nat Clin Pract Endocrinol Metab 2006;2(1):42-52.

[235] Carlomagno F, Guida T, Anaganti S, et al. Disease associated mutations at valine 804 in the RET receptor tyrosine kinase confer resistance to selective kinase inhibitors. Oncogene 2004;23:6056-63.

[236] Pao W, Miller VA. Epidermal growth factor receptor mutations, smallmolecule kinase inhibitors, and non-small-cell lung cancer: current knowledge and future directions. J Clin Oncol 2005;23:2556-68.

[237] Kim DW, Jo YS, Jung HS, et al. An orally administered multitarget tyrosine kinase inhibitor, SU11248, is a novel potent inhibitor of thyroid oncogenic RET/papillary thyroid cancer kinases. J Clin Endocr Metab 2006;91:4070-6.

[238] Carlomagno F, Vitagliano D, Guida T, et al. The kinase inhibitor PP1 blocks tumorigenesis induced by RET oncogenes. Cancer Res 2002;62:1077-82.

[239] Carlomagno F, Vitagliano D, Guida T, et al. Efficient inhibition of RET/papillary thyroid carcinoma oncogenic kinases by 4-amino-5(4-chloro-phenyl)-7-(t-butyl)pyrazolo[3,4-d]pyrimidine (PP2). J Clin Endocrinol Metab 2003;88:1897-902.

[240] Garcia-Rostan G, Zhao H, Camp RL, et al. Ras mutations are associated with aggressive tumor phenotypes and poor prognosis in thyroid cancer. J Clin Oncol 2003;21:3226-35.

[241] Fagin JA. Minireview: branded from the start-distinct oncogenic initiating events may determine tumor fate in the thyroid. Mol Endocrinol 2002;16:903-11.

[242] Saavedra HI, Knauf JA, Shirokawa JM, et al. The RAS oncogene induces genomic instability in thyroid PCCL3 cells via the MAPK pathway. Oncogene 2000;19:3948-54.

[243] Sansal I, Sellers WR. The biology and clinical relevance of the PTEN tumor suppressor pathway. J Clin Oncol 2004;22(14):63.

[244] Furuya F, Lu C, Willingham MC, Cheng SY. Inhibition of phosphatidylinositol 3-kinase delays tumor progression and blocks metastatic spread in a mouse model of thyroid cancer. Carcinogenesis 2007;28(12):2451-8.

[245] Liu P, Cheng H, Roberts TM, Zhao JJ. Targeting the phosphoinositide 3-kinase pathway in cancer. Nat Rev Drug Discov 2009;8(8): 627-44.

[246] Placzkowski KA, Reddi HV, Grebe SK, Eberhardt NL, McIver B. The role of the PAX8/PPARgamma fusion oncogene in thyroid cancer. PPAR Res 2008;2008:672829.

[247] Karin M. NF-кB as a critical link between inflammation and cancer. Cold Spring Harb Perspect Biol 2009;1(5):41.

[248] Liu D, Xing M. Potent inhibition of thyroid cancer cells by the MEK inhibitor PD0325901 and its potentiation by suppression of the PI3K and NF-кB pathways. Thyroid 2008;18(8):853-64.

[249] Xing M. Minireview: gene methylation in thyroid tumorigenesis. Endocrinology 2007;148(3):948-53.

[250] Akagi T, Luong QT, Gui D, et al. Induction of sodium iodide symporter gene and molecular characterisation of HNF3 $3 / F$ FoxA2, TTF-1 and C/EBP $\beta$ in thyroid carcinoma cells. $\mathrm{Br} \mathrm{J}$ Cancer 2008;99(5):781-8.

[251] Kouzarides T. Chromatin modifications their function. Cell 2007;128(4):693-705.

[252] Ting AH, McGarvey KM, Baylin SB. The cancer epigenome-components and functional correlates. Genes Dev 2006;20(23):3215-31.

[253] Riesco-Eizaguirre G, Santisteban P. New insights in thyroid follicular cell biology and its impact in thyroid cancer therapy. Endocr Relat Cancer 2007;14(4):957-77.

[254] Lim SM, Chang H, Yoon MJ, et al. A multicenter, phase II trial of everolimus in locally advanced or metastatic thyroid cancer of all histologic subtypes. Ann Oncol 2013;24(12):3089-94.

[255] Ball DW, Sherman SI, Jarzab B, et al. Lenvatinib treatment of advanced RAI-refractory differentiated thyroid cancer (DTC): cytokine and angiogenic factor (CAF) profiling in combination with tumor genetic analysis to identify markers associated with response. J Clin Oncol 2012;30(15):5518.

[256] Pennell NA, Daniels GH, Haddad RI, et al. A phase II study of gefitinib in patients with advanced thyroid cancer. Thyroid 2008;18(3): $317-23$.

[257] Sherman EJ, Fury MG, Tuttle RM, et al. Phase II study of depsipeptide (DEP) in radioiodine (RAI)-refractory metastatic nonmedullary thyroid carcinoma. J Clin Oncol 2009;27(15S):6059.

[258] Woyach JA, Kloos RT, Ringel MD, et al. Lack of therapeutic effect of the histone deacetylase inhibitor vorinostat in patients with metastatic radioiodine-refractory thyroid carcinoma. J Clin Endocrinol Metab 2009;94(1):164-70. 
[259] Cohen EE, Rosen LS, Vokes EE, et al. Axitinib is an active treatment for all histologic subtypes of advanced thyroid cancer: results from a phase II study. J Clin Oncol 2008;26(29):4708-13.

[260] Gupta-Abramson V, Troxel AB, Nellore A, et al. Phase II trial of sorafenib in advanced thyroid cancer. J Clin Oncol 2008;26(29):4714-9.

[261] Kelly WK, O'Connor OA, Krug LM, et al. Phase I study of an oral histone deacetylase inhibitor, suberoylanilide hydroxamic acid, in patients with advanced cancer. J Clin Oncol 2005;23(17):3923-31.

[262] Sherman SI, Wirth LJ, Droz JP, et al. Motesanib diphosphate in progressive differentiated thyroid cancer. $N$ Engl $\mathrm{J}$ Med 2008;359(1):31-42.

[263] Ain KB, Lee C, Williams KD, Phase II. trial of thalidomide for therapy of radioiodine-unresponsive and rapidly progressive thyroid carcinomas. Thyroid 2007;17(7):663-70.

[264] Bible KC, Suman VJ, Molina JR, et al. Efficacy of pazopanib in progressive, radioiodine-refractory, metastatic differentiated thyroid cancers: results of a phase 2 consortium study. Lancet Oncol 2010;11(10):962-72

[265] Zhang Y, Guessous F, Kofman A, Schiff D, Abounader R. XL184, a MET, VEGFR-2 and RET kinase inhibitor for the treatment of thyroid cancer, glioblastoma multiforme and NSCLC. IDrugs 2010;13(2):112-21.

[266] de Groot JW, Zonnenberg BA, van Ufford-Mannesse PQ, et al. A phase II trial of imatinib therapy for metastatic medullary thyroid carcinoma. J Clin Endocrinol Metab 2007;92(9):3466-9.

[267] Mrozek E, Kloos RT, Ringel MD, et al. Phase II study of celecoxib in metastatic differentiated thyroid carcinoma. J Clin Endocrinol Metab 2006;91(6):2201-4.

[268] Cooney MM, Savvides P, Agarwala S, et al. Phase II study of combretastatin A4 phosphate (CA4P) in patients with advanced anaplastic thyroid carcinoma (ATC). J Clin Oncol 2006;24(18).

[269] Cohen EE, Needles BM, Cullen KJ, et al. Phase 2 study of sunitinib in refractory thyroid cancer. J Clin Oncol 2008;26(15):6025.

[270] Wells Jr SA, Robinson BG, Gagel RF, et al. Vandetanib in patients with locally advanced or metastatic medullary thyroid cancer: a randomized, double-blind phase III trial. J Clin Oncol 2012;30(2): 134-41.

[271] Wells Jr SA, Gosnell JE, Gagel RF, et al. Vandetanib in metastatic hereditary medullary thyroid cancer: follow-up results of an openlabel phase II trial. J Clin Oncol 2007;25(18):6018.

[272] Ain KB, Lee C, Holbrook KM, Dziba JM, Williams KD. Phase II study of lenalidomide in distantly metastatic, rapidly progressive, and radioiodine-unresponsive thyroid carcinomas: preliminary results. J Clin Oncol 2008;26(15):6027

[273] Elisei R, Schlumberger MJ, Müller SP, et al. Cabozantinib in progressive medullary thyroid cancer. J Clin Oncol 2013;31(29):3639-46.

[274] Meier CA, Braverman LE, Ebner SA, et al. Diagnostic use of recombinant human thyrotropin in patients with thyroid carcinoma (phase I/II study). J Clin Endocrinol Metab 1994;78(1):188-96.

[275] Mooney CJ, Nagaiah G, Fu P, et al. A phase II trial of fosbretabulin in advanced anaplastic thyroid carcinoma and correlation of baseline serum-soluble intracellular adhesion molecule-1 with outcome. Thyroid 2009; 19(3):233-40.

[276] Piekarz R, Luchenko V, Draper D, et al. Phase I trial of romidepsin, a histone deacetylase inhibitor, given on days one, three and five in patients with thyroid and other advanced cancers. J Clin Oncol 2008;26(15):3571

[277] Argiris A, Agarwala SS, Karamouzis MV, Burmeister LA, Carty SE. A phase II trial of doxorubicin and interferon alpha $2 \mathrm{~b}$ in advanced, non-medullary thyroid cancer. Invest New Drugs 2008;26(2):183-8.

[278] Kebebew E, Peng M, Reiff E, et al. A phase II trial of rosiglitazone in patients with thyroglobulin-positive and radioiodine-negative differentiated thyroid cancer. Surgery 2006;140(6):960-6.

[279] www.clinicaltrials.gov

[280] Liu D, Xing J, Trink B, Xing M. BRAF mutation-selective inhibition of thyroid cancer cells by the novel MEK inhibitor RDEA119 and genetic-potentiated synergism with the mTOR inhibitor temsirolimus. Int J Cancer 2010;127(12):2965-73.

[281] Jin N, Jiang T, Rosen DM, Nelkin BD, Ball DW. Synergistic action of a RAF inhibitor and a dual PI3K/mTOR inhibitor in thyroid cancer. Clin Cancer Res 2013;17(20):6482-9.

[282] Liu R, Liu D, Xing M. The Akt inhibitor MK2206 synergizes, but perifosine antagonizes, the BRAF(V600E) inhibitor PLX4032 and the MEK1/2 inhibitor AZD6244 in the inhibition of thyroid cancer cells. J Clin Endocrinol Metab 2012;97(2):E173-82.

[283] Xing M. Genetic-targeted therapy of thyroid cancer: a real promise. Thyroid 2009;19(8):805-9.

[284] Kloos RT, Ringel MD, Knopp MV, et al. Phase II trial of sorafenib in metastatic thyroid cancer. J Clin Oncol 2009;27(10):1675-84.

[285] Ahmed M, Barbachano Y, Riddell A, et al. Analysis of the efficacy and toxicity of sorafenib in thyroid cancer: a phase II study in a UK based population. Eur J Endocrinol 2011;165(2):315-22.

[286] Flaherty KT, Puzanov I, Kim KB, et al. Inhibition of mutated, activated BRAF in metastatic melanoma. N Engl J Med 2010;363(9):809-19.

[287] Hou P, Bojdani E, Xing M. Induction of thyroid gene expression and radioiodine uptake in thyroid cancer cells by targeting major signaling pathways. J Clin Endocrinol Metab 2010;95(2):820-8.

\section{Biographies}

Özgür Ömür is an Associate Professor of Nuclear Medicine at Ege University, Medical School, İzmir, Turkey. She graduated from Ege University, School of Medicine in 1996 and earned her residence in Department of Nuclear Medicine of Ege University in 2001. Since then, she has been practicing in the Department of Nuclear Medicine. Dr. Ömür's practice focuses on the treatment of differentiated thyroid cancer and nuclear cardiology. She is also specialized in oncological imaging with a special interest on positron emission tomography. Dr. Ömür is a member of the Turkish Association of Nuclear Medicine, European Association of Nuclear Medicine and Turkish Board of Nuclear Medicine.

Yusuf Baran is an associate professor in the Department of Molecular Biology and Genetics, at İzmir Institute of Technology. His career in cancer research began at Middle East Technical University (METU) which is renowned in the area of molecular biology. Understanding cell death mechanisms in cancer was the aim of his masters and doctoral education which was completed at METU. During his doctoral work, he worked in the Medical University of South Carolina, Holling Cancer Center, USA. Thereafter he joined the Department of Molecular Biology and Genetics of İzmir Institute of Technology where he became associate professor. He established the "Cancer Genetics Research Laboratory" in this university. Dr. Baran is a member of the Global Young Academy, Turkish Academy of Sciences Young Investigator Programme and Turkish Academy of Sciences, Cancer Research Group. He also serves on the advisory board of The Scientific and Technical Research Council of Turkey, the country's main science funding agency. He is also a director of the Biotechnology and Bioengineering Application and Research Center. He was recently selected as a 2013 Young Scientist by the World Economic Forum. 